\title{
Variation in and risk factors for paediatric inpatient all-cause mortality in a low income setting: data from an emerging clinical information network
}

David Gathara ${ }^{1 *}$, Lucas Malla ${ }^{1,2}$, Philip Ayieko', Stella Karuri ${ }^{1}$, Rachel Nyamai ${ }^{3}$, Grace Irimu ${ }^{1,4}$, Michael Boele van Hensbroek ${ }^{5}$, Elizabeth Allen ${ }^{6}$, Mike English ${ }^{1,2}$ and the Clinical Information Network

\begin{abstract}
Background: Hospital mortality data can inform planning for health interventions and may help optimize resource allocation if they are reliable and appropriately interpreted. However such data are often not available in low income countries including Kenya.

Methods: Data from the Clinical Information Network covering 12 county hospitals' paediatric admissions aged 2-59 months for the periods September 2013 to March 2015 were used to describe mortality across differing contexts and to explore whether simple clinical characteristics used to classify severity of illness in common treatment guidelines are consistently associated with inpatient mortality. Regression models accounting for hospital identity and malaria prevalence (low or high) were used. Multiple imputation for missing data was based on a missing at random assumption with sensitivity analyses based on pattern mixture missing not at random assumptions.

Results: The overall cluster adjusted crude mortality rate across hospitals was $6 \cdot 2 \%$ with an almost 5 fold variation across sites (95\% Cl $4 \cdot 9$ to $7 \cdot 8$; range $2 \cdot 1 \%-11 \cdot 0 \%)$. Hospital identity was significantly associated with mortality. Clinical features included in guidelines for common diseases to assess severity of illness were consistently associated with mortality in multivariable analyses ( $A R O C=0 \cdot 86)$.

Conclusion: All-cause mortality is highly variable across hospitals and associated with clinical risk factors identified in disease specific guidelines. A panel of these clinical features may provide a basic common data framework as part of improved health information systems to support evaluations of quality and outcomes of care at scale and inform health system strengthening efforts.
\end{abstract}

Keywords: Mortality, Quality of care, Paediatrics, Hospital, Variability, Clinical risk factors

\section{Background}

It is important for a health system to have an accsurate picture of overall (crude) and cause-specific hospital mortality. Although using mortality or risk adjusted mortality as an indicator of quality of care is contested because it is hard to adjust for case-mix or the severity of illness on arrival (case-severity) [1-4]

\footnotetext{
* Correspondence: dgathara@kemri-wellcome.org

'Department of Public Health Research, KEMRI Wellcome Trust Research

Programme, P.O. Box 43640 00100, Nairobi, Kenya

Full list of author information is available at the end of the article
}

the presence of 3.variation in mortality may point to possible inequalities in population health, access or resource provision that can be addressed. Yet, little attention has been paid to understanding and exploring hospital mortality and its variability in African settings, perhaps because routinely reported data are often of poor quality [5].

In this report our aim is to contribute to efforts to understand health system performance and describe mortality and its variability. We also explore whether simple clinical characteristics used to classify severity 
of common childhood illness are consistently associated with inpatient mortality. Demonstrating the latter provides a rationale for reinforcing their widespread clinical use and for considering them as components of a common data framework for paediatric admissions. A common data framework (potentially included in emerging electronic record systems) could improve our ability to characterise hospitals by their case-mix and case severity and inform health system strengthening efforts in support of universal access to quality health care.

\section{Methods}

\section{Study setting}

In 2014, Kenya had a gross domestic product of 1246 US dollars per capita after rebasing [6] and the underfive mortality was 58.3 per 1000 live births according to 2013 estimates [7, 8]. It has good immunization coverage of $90 \%$ for the 3rd dose of the pentavalent vaccine (introduced in 2002 and containing Diphtheria, Pertussis, Tetanus, Hepatitis B and Haemophilus influenzae type B antigens) and $85 \%$ for the 10 -valent pneumococcal conjugate vaccine (PCV 10, introduced in 2011) [7].

The study takes advantage of a recently established clinical information network (CIN) comprised of 13 county referral hospitals. However, one county hospital was excluded from the analyses presented because of persistent problems with data collection. In total $12 \mathrm{fa}$ cilities (11 counties) are therefore included in this analysis. The selection and geographic location of hospitals is presented in detail in panel 1, Table 1 and Fig. 1. In brief, CIN is a partnership between researchers, the Ministry of Health and paediatricians and is a pragmatic research database collecting patient level data from all paediatric admissions with aims at improving use of information in policy and practice.

Panel 1: Selection of the Clinical Information Network sites and Case Sampling

Kenya devolved health care provision to 47 county administrations in 2013 with the national Ministry of Health retaining responsibility for monitoring and evaluation amongst other areas. The clinical information network (CIN) was designed as a partnership between researchers, the Ministry of Health and paediatricians and is a pragmatic research database collecting patient level data from all paediatric admissions with aims at improving use of information in policy and practice. Twelve counties were first identified purposefully with the Ministry of Health to ensure the feasibility of the project while representing two main groupings based on the prevalence of malaria as an admission clinical diagnosis: high $(>50 \%)$ and low $(<20 \%)$. Within counties tertiary level facilities were excluded (found in 1 of the 12 counties) but public hospitals providing first referral level care (also called secondary level) within these counties and estimated to have at least 1000 paediatric admissions per year were considered eligible. One hospital was then purposefully selected from each county except in the largest urban county serving a population of over 3 million from which two hospitals were included. This resulted in two geographic clusters of hospitals (Fig. 1).

These hospitals were invited to join the proposed clinical information network (CIN) after its nature and purpose was explained to each hospitals' management team and paediatric departments and their agreement sought. Characteristics of hospitals in the CIN are presented in Table 1.

Table 1 Characteristics of hospitals in the clinical information network

\begin{tabular}{|c|c|c|c|c|c|c|c|c|c|}
\hline Hospital & $\begin{array}{l}\text { Bed } \\
\text { capacity }\end{array}$ & $\begin{array}{l}\text { Duration of } \\
\text { data collection } \\
\text { in months }\end{array}$ & $\begin{array}{l}\text { Cases available for } \\
\text { analysis -minimum } \\
\text { dataset }\end{array}$ & $\begin{array}{l}\text { Cases available } \\
\text { for analysis -full } \\
\text { dataset }\end{array}$ & $\begin{array}{l}\text { Diarrhoea } \\
\text { admissions }\end{array}$ & $\begin{array}{l}\text { Pneumonia } \\
\text { admissions }\end{array}$ & $\begin{array}{l}\text { Malaria } \\
\text { admissions }\end{array}$ & $\begin{array}{l}\text { PMTCT HIV } \\
\text { prevalence }\end{array}$ & $\begin{array}{l}\text { Percentage } \\
\text { living in poverty } \\
\text { in the county }\end{array}$ \\
\hline$A$ & 67 & 18 & 4757 & 2081 & 1659 (34.9) & $2351(49 \cdot 4)$ & $108(2 \cdot 3)$ & 6.7 & 26 \\
\hline B & 35 & 18 & 1853 & 1685 & $446(24 \cdot 1)$ & $1029(55 \cdot 5)$ & $65(3.5)$ & 6.8 & 56 \\
\hline C & 41 & 18 & 3517 & 1989 & $1063(30 \cdot 2)$ & $1650(46 \cdot 9)$ & $317(9 \cdot 0)$ & 9.7 & 21 \\
\hline D & 42 & 18 & 2445 & 2217 & 747 (30.6) & $1420(58 \cdot 1)$ & $210(8 \cdot 6)$ & 9.7 & 21 \\
\hline$E$ & 29 & 13 & 1982 & 1774 & $436(22 \cdot 0)$ & $1057(53 \cdot 3)$ & $138(7 \cdot 0)$ & 2.8 & 25 \\
\hline $\mathrm{F}$ & 63 & 13 & 2440 & 2215 & $663(27 \cdot 2)$ & $1379(56 \cdot 5)$ & $252(10 \cdot 3)$ & 2.8 & 41 \\
\hline G & 32 & 13 & 1881 & 1726 & $391(20 \cdot 8)$ & $886(47 \cdot 1)$ & $10(0 \cdot 5)$ & 5.5 & 31 \\
\hline $\mathrm{H}$ & 29 & 13 & 2146 & 1767 & $531(24 \cdot 7)$ & $548(25 \cdot 5)$ & $1238(57 \cdot 7)$ & 20.5 & 45 \\
\hline I & 35 & 17 & 4175 & 3812 & $1106(26 \cdot 5)$ & $1224(29 \cdot 3)$ & $3640(87 \cdot 2)$ & 4.5 & 51 \\
\hline$J$ & 21 & 17 & 2209 & 1729 & $267(12 \cdot 1)$ & $504(22 \cdot 8)$ & $1416(64 \cdot 1)$ & 11.8 & 40 \\
\hline K & 32 & 17 & 3066 & 2454 & $474(15 \cdot 5)$ & $867(28 \cdot 3)$ & $2020(65 \cdot 9)$ & 13.9 & 65 \\
\hline$L$ & 38 & 17 & 3270 & 2875 & $967(29.6)$ & $1433(43 \cdot 8)$ & 1993 (60.9) & 9.3 & 49 \\
\hline
\end{tabular}

Hospital workload, epidemiological diversity, catchment population poverty index and data available for the analysis 


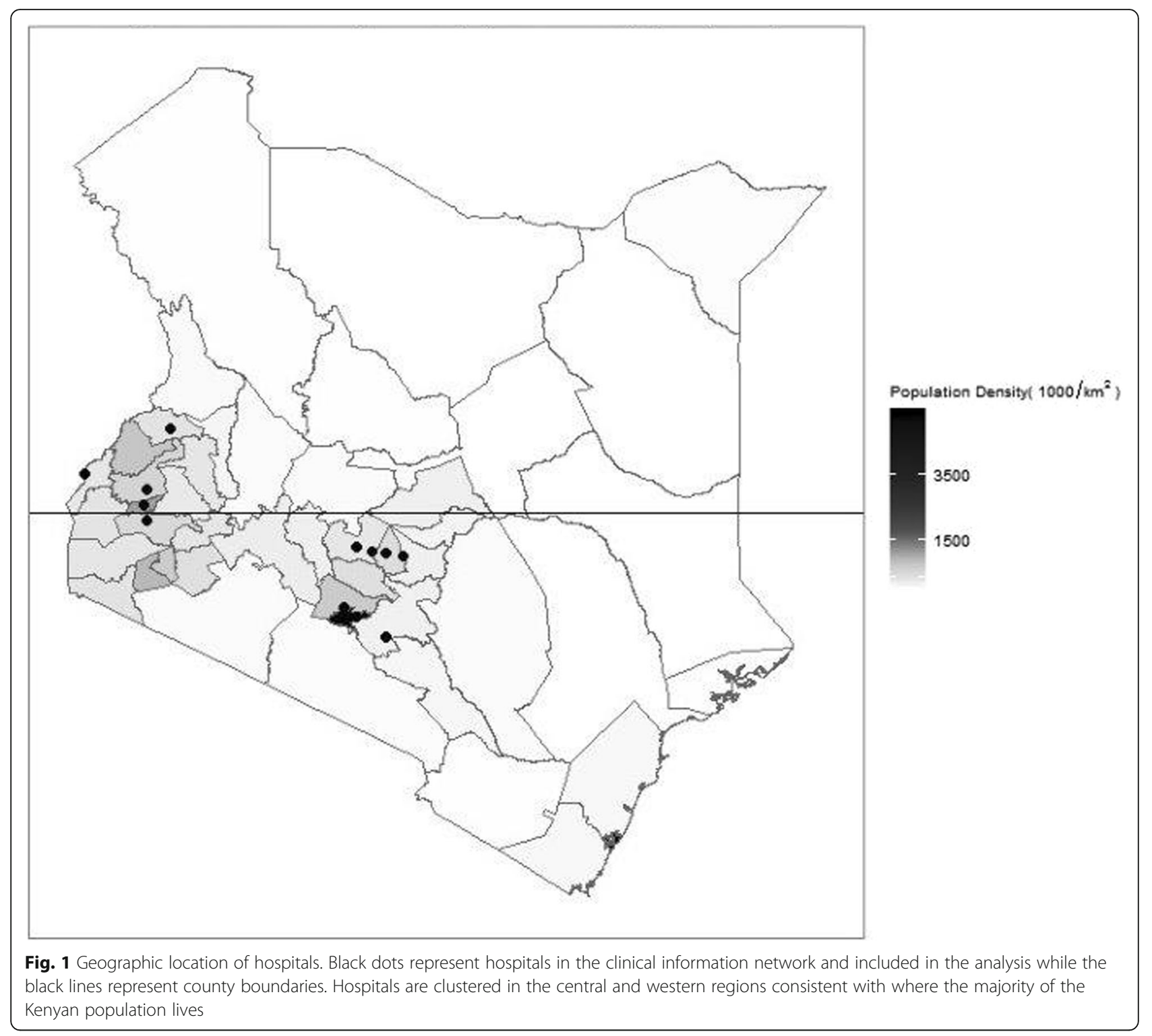

In brief, the CIN collects core data that should be part of the routine health information system (RHIS) (the RHIS dataset) on all children admitted to hospital after their discharge (see below). In 10 of the 12 hospitals a comprehensive set of additional data were also collected on all admissions but due to high workloads in two hospitals (A and C) such comprehensive data were collected only on a random sample of $35 \%$ and $65 \%$ of the admissions respectively.

\section{Study population}

The population of interest for this report is restricted to children aged 2-59 months, the subjects of available, evidence-based clinical guidelines [9]. Hospitals joined the network in a staggered fashion from September 2013 over a period of 6 months, the period to March 2015 therefore provides at least one full calendar year for analysis from each hospital. In these hospitals, diagnoses at the time of discharge or death are clinician defined and informed by access to only very basic diagnostics (for example malaria blood slide but not blood culture) and post-mortems are done extremely rarely.

\section{Data collection}

Hospitals were encouraged to fully implement a structured pediatric admission record (PAR) that has been shown to improve documentation of core clinical characteristics at admission [10] and which was 
adopted by the Ministry of Health in 2010 as the admission encounter form for district hospitals [11]. Data were collected from the routine case record in an approach described in full elsewhere [12]. In brief, data were abstracted on the day following discharge from each child's case record and entered directly onto a computer in a REDCap [13] database with in-built range and validity checks. Data clerks were trained centrally as a team prior to data collection in hospitals according to detailed, written standard operating procedures provided as a manual. At the end of every day before data were synchronized to a central database, the clerk checked on-site for errors, completeness and consistency with locally executed 'cleaning' programmes. Any inconsistencies or errors identified were corrected after verification from the case record. Throughout the study period clerks were coordinated and supervised by a research team member who telephoned approximately weekly and made visits approximately two-monthly when ongoing training to improve data collection was conducted.

\section{Analysis}

The Routine Health Information System (RHIS) dataset includes patient age, sex, weight, diagnoses and outcome. Secondary variables described below were generated from these. Age was categorised into 2-6, 7-11, and 1259 months groups based on differences in observed risks of death in the dataset. The number of diagnoses made at admission (comorbidities) was categorised into no comorbidity, one comorbidity, two comorbidities and three or more comorbidities. Weight-for-age z-score (WAZ) measurement was classified according to standard WHO reference tables for age, weight and gender as follows: children with a $\mathrm{Z}$ score, $>-1$ were classified as normal, children with a $Z$ score $<=-1$ and $>-2$ were classified as mildly malnourished, children with a $Z$ score, $<=-2$ and $>-3$ as moderately malnourished, and children with a $Z$ score $<=-3$ as severely malnourished. The RHIS dataset was used to explore those associations between patient characteristics and mortality made possible if the routine health information system were functioning well. A secondary variable was generated to categorise hospital groups by malaria prevalence as an admission diagnosis (high $>50 \%$; low $<20 \%$ ). This grouping has some association with HIV prevalence and poverty levels (Table 1).

The comprehensive dataset included an additional checklist of clinical symptoms and signs recorded by the duty clinician on the paediatric admission record. These include danger signs and other signs promoted by Integrated Management of Childhood Illness guidelines [14] and those previously associated with all-cause or disease-specific mortality [15-19] that are used in national [20] and World Health Organisation [21] evidence-based guidelines to guide diagnosis, severity classification and treatment for the commonest causes of paediatric hospital admission (malaria, pneumonia, diarrhoea/dehydration, malnutrition, meningitis, anaemia and asthma). They are listed in Table 2. As there were few observations in each of the V (2\%), P (4\%) and $\mathrm{U}(<1 \%)$ categories of the AVPU scale these observations were re-categorised into Alert and Not alert.

\section{Statistical analysis}

All patients without outcome data or with an implausible or missing date of admission, discharge or death were dropped from the analysis (see Fig. 2). Using the RHIS dataset we present hospital specific crude mortality rates and accompanying confidence intervals. To explore whether hospital mortality was associated with hospital identity, we used the RHIS dataset and fitted a fixed effects model with hospital but no other covariates and compared this to a null model using a likelihood ratio test (LRT). Hospitals were retained as fixed effects in all multivariable models because of significant associations with mortality and because we had only a small, non-random sample of hospitals (considering hospitals identities as random effects made no appreciable difference to results, data not shown).

The data available on clinical signs, symptoms and diagnoses are presented as hospital specific proportions in Table 2 and illustrate the variability across sites. We used logistic regression without adjustment to explore associations with mortality for each variable but without hospitals as fixed effects (Table 3 ). We then built multivariable models to explore associations of key clinical factors with mortality. We included malaria prevalence as a fixed effect in the multivariable models and explored for interaction between the risk factors and malaria prevalence. We used a multivariable model (model 1) based on the RHIS dataset to explore the ability of these data to explain mortality (Table 2). Model 2 included all variables in the comprehensive dataset (Table 2) in a complete case analysis including interaction terms for malaria prevalence. This included only $57 \%$ of all cases as a result of list-wise deletion of records with any missing data (see Fig. 2). The degree of missingness, represented as a proportion, varied by hospital and variable (Table 2). To address the missing data problem multiple imputation was used (panel 2) with the validity of results explored in sensitivity analyses (panel 3).

\section{Panel 2: Handling missing data}

We explored and subsequently assumed a missing at random (MAR) mechanism as a basis for multiple imputation using the chained equation methods proposed by van Buuren [22] and Raghunathan [23]. Imputation was based on 100 iterations and 10 datasets as has been 


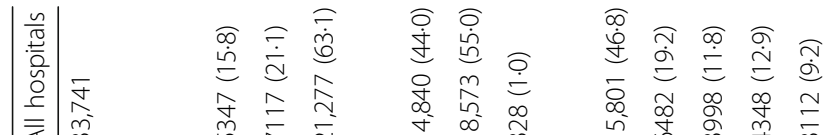

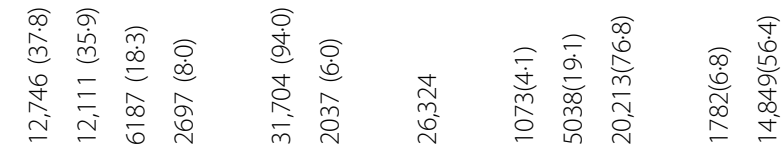

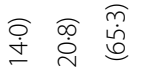

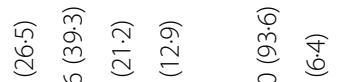

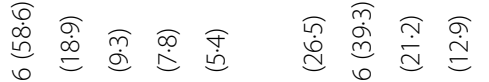

象

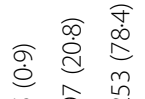

$\underset{\dot{\theta}}{\stackrel{\pi}{\hat{n}}}$

$-\stackrel{\curvearrowright}{\curvearrowright}$

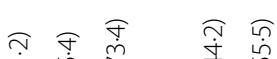

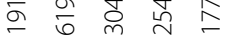

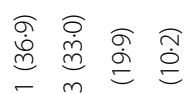

बे

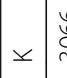

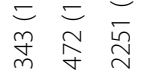

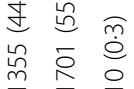

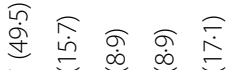

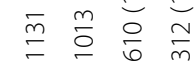

崔

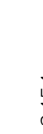

崩 ๙ิ

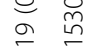

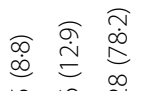

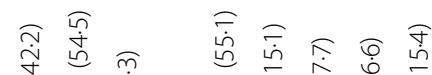

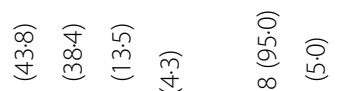

坚 $\underset{\sim}{\infty} \stackrel{\infty}{N}$

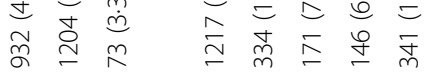

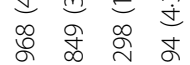

吕 $=$

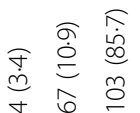

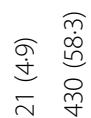

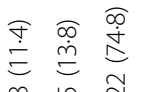

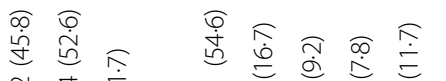

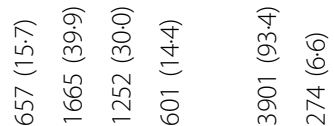

政

oิ

$\simeq \pm$

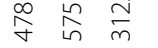

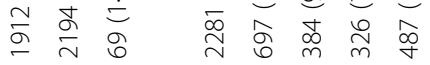

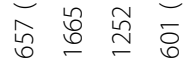

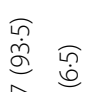

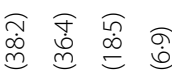

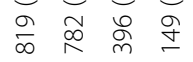

ठ્ટે

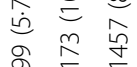



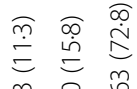

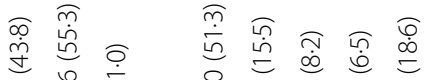

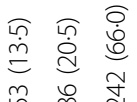

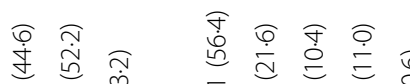

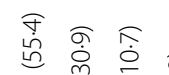

ז

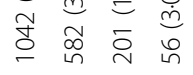

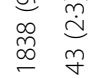

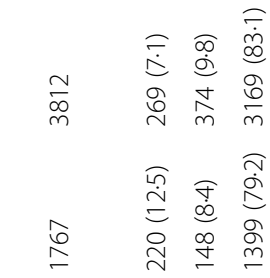

$\simeq$ a

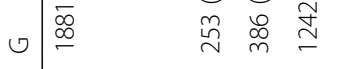

$\underset{\infty}{\infty} \bar{\infty} \frac{\sqrt{n}}{\sigma}$

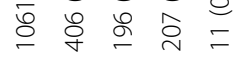

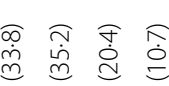

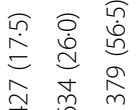

高 $\underset{\dot{\sigma}}{\dot{\dot{y}}}$

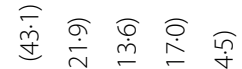

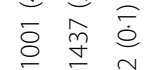

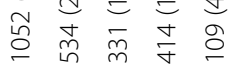

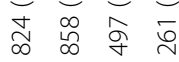

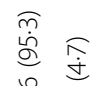

๙ุ

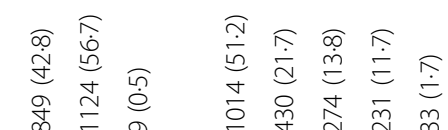

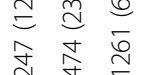

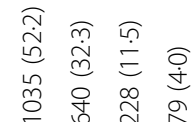

$\underset{\sim}{\sim} \stackrel{⿱}{=}$

$\stackrel{\widehat{\infty}}{\dot{m}}$

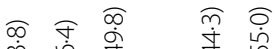

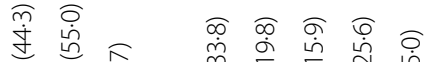

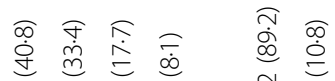

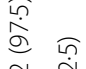

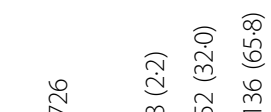

产

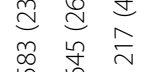

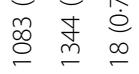

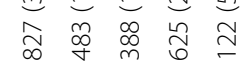

S.

$\stackrel{\infty}{\sim} \underset{n}{\sim}$

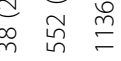

西

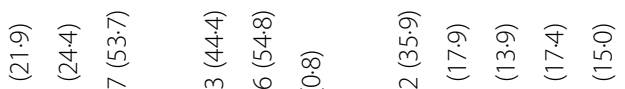

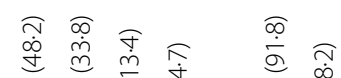

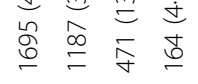

^ิ

$\underset{\dot{i}}{\underline{i}} \stackrel{0}{0}$

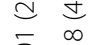

$\bar{q} \stackrel{\infty}{i}$

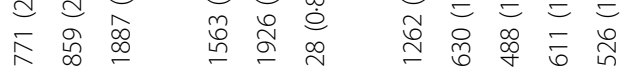

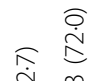

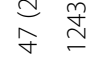

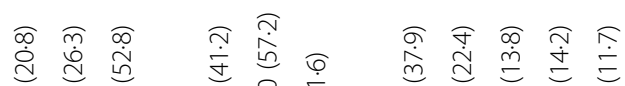

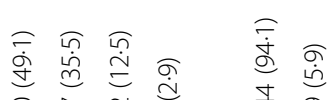

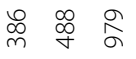

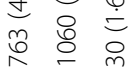

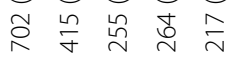

สํํำ

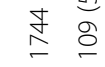

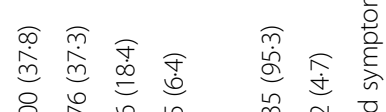

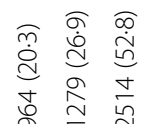

寽芯

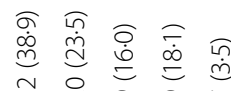

규요

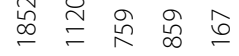
$\stackrel{\infty}{\subseteq} \stackrel{\infty}{\infty} \stackrel{\sim}{m}$

盛

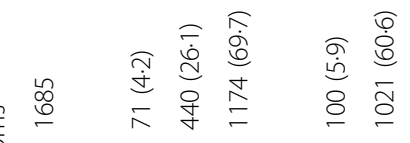

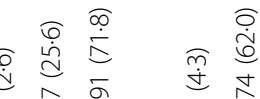

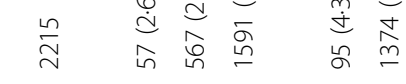
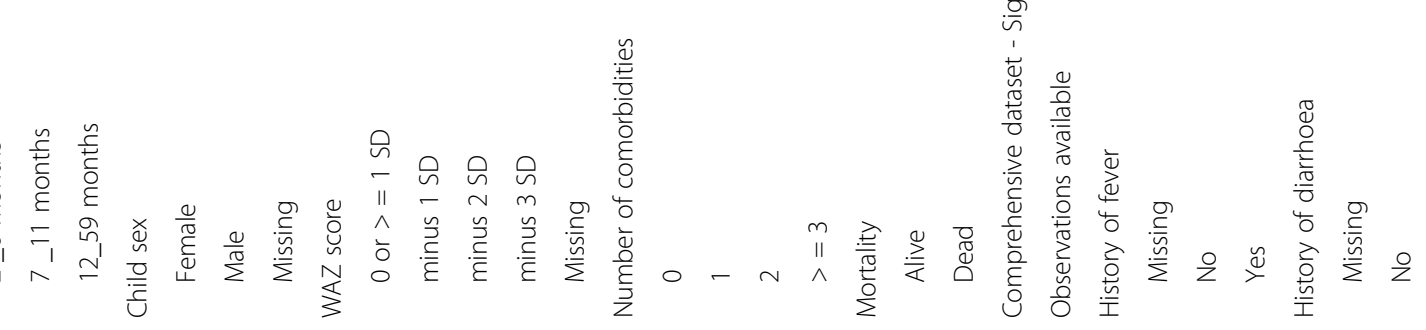


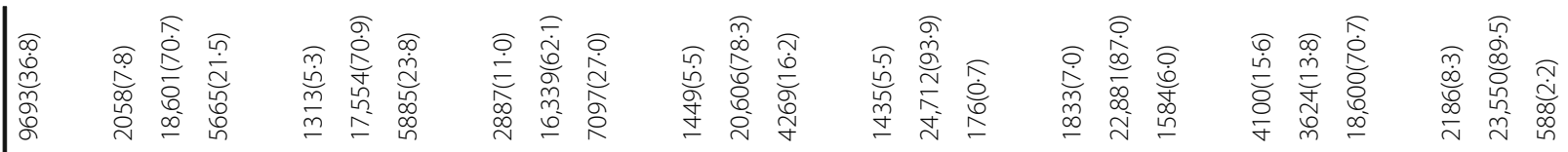

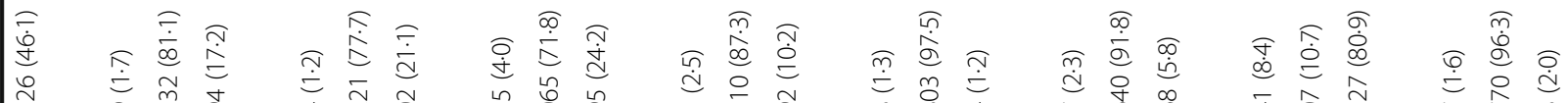

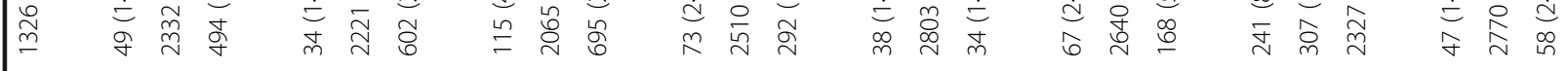

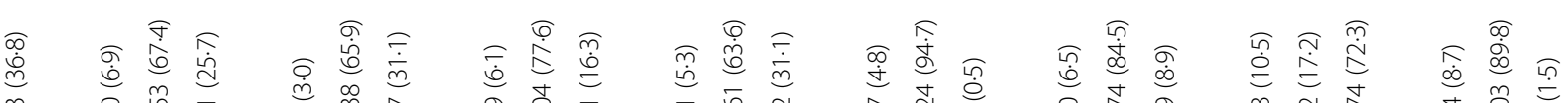

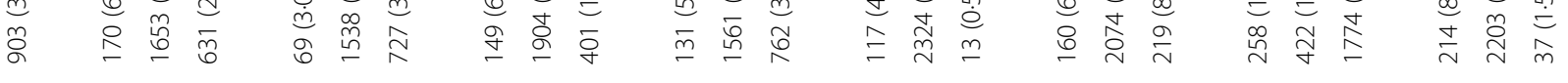

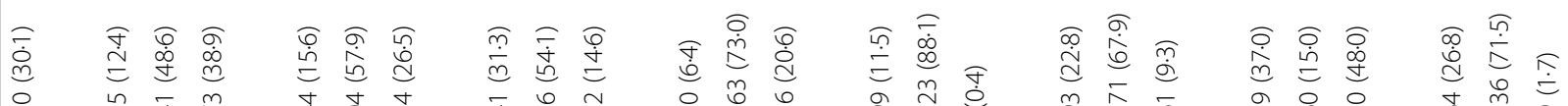

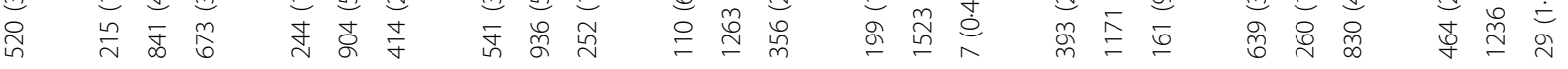

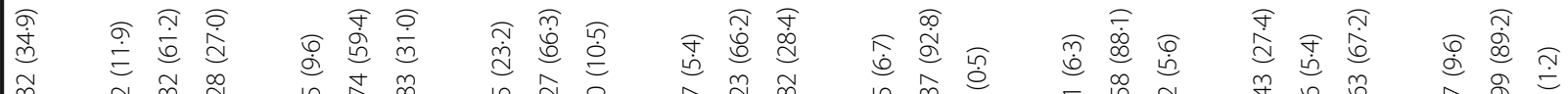

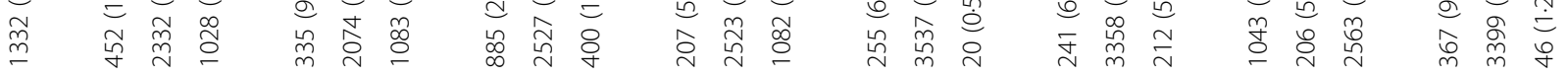

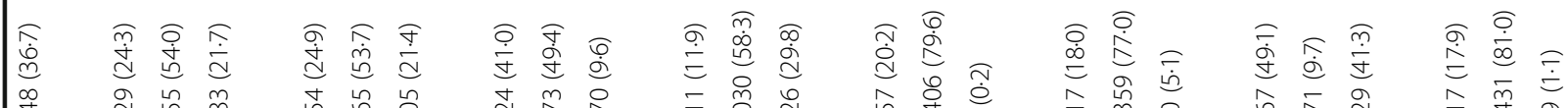

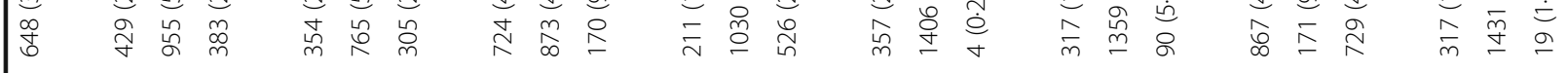

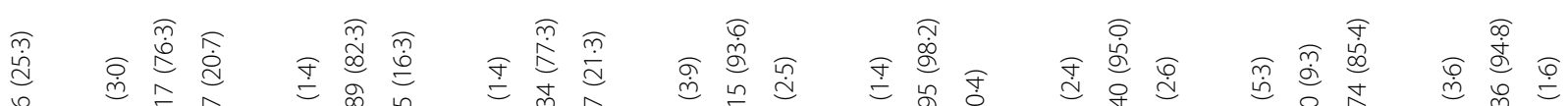

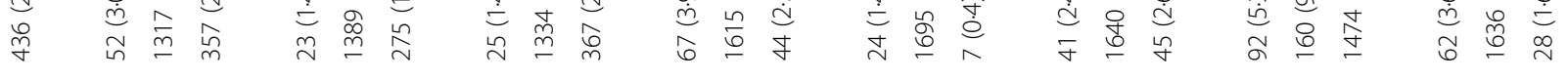

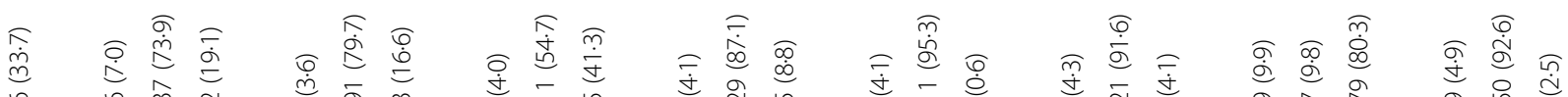

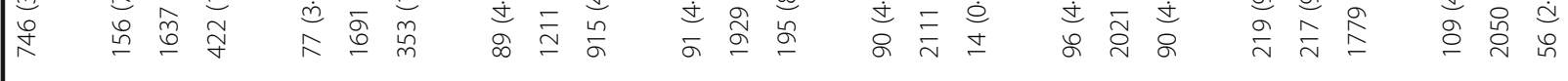

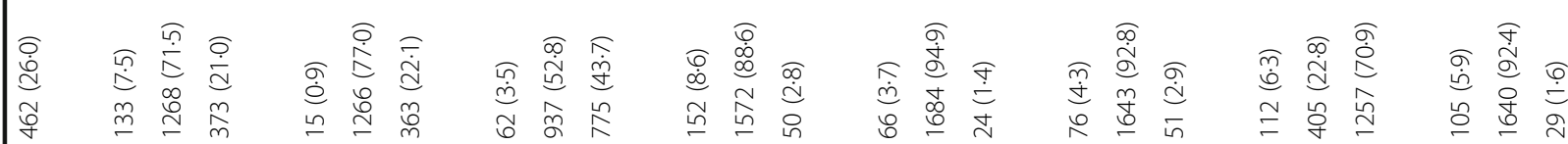

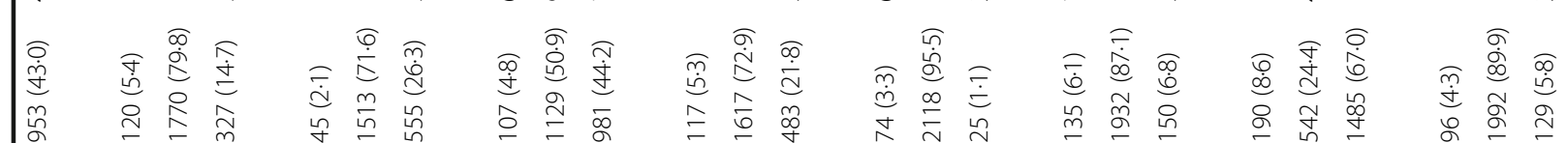

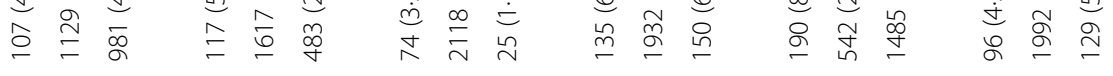

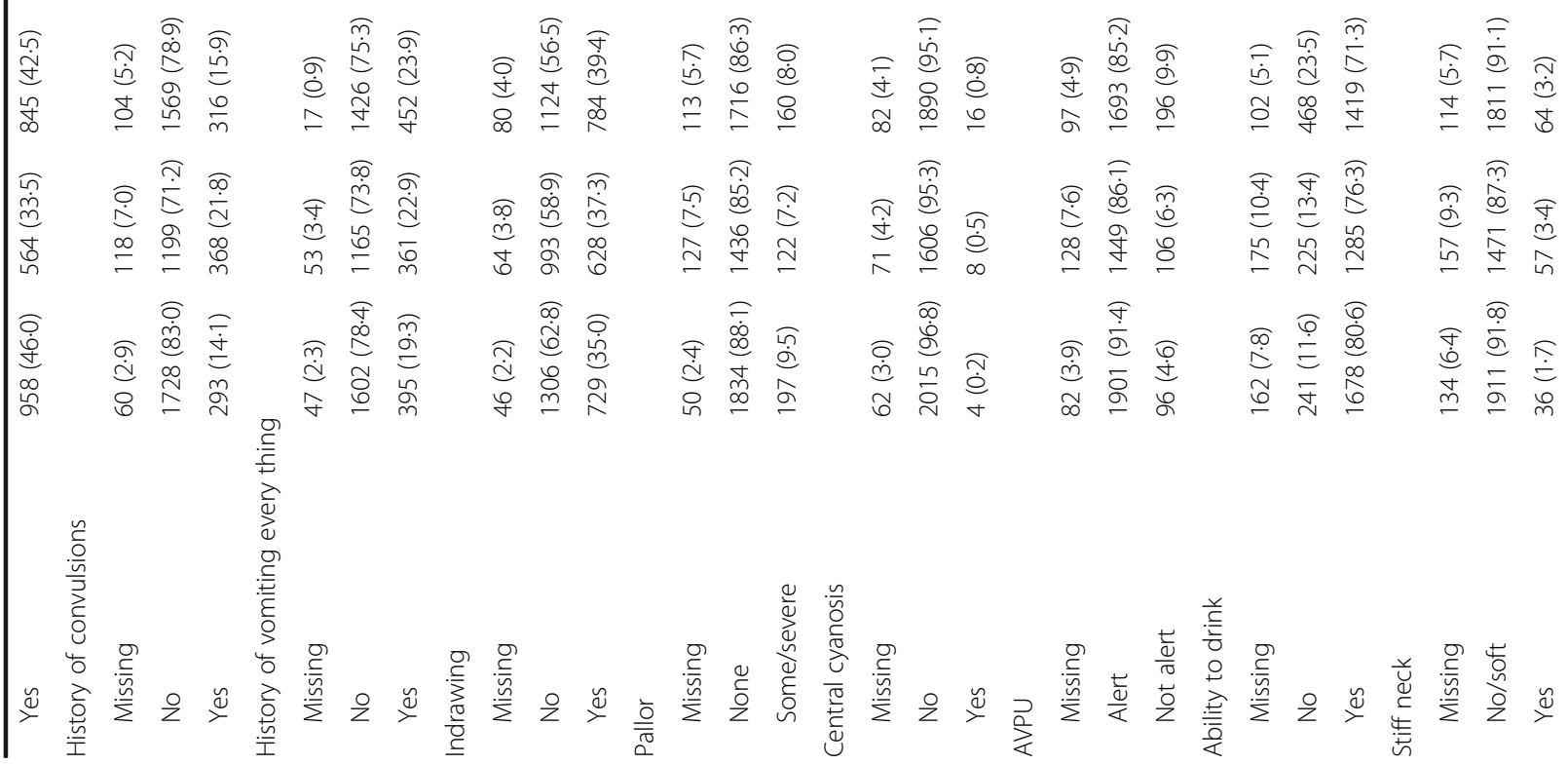




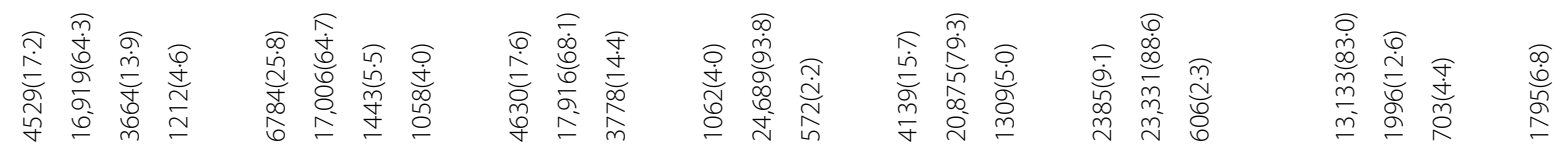

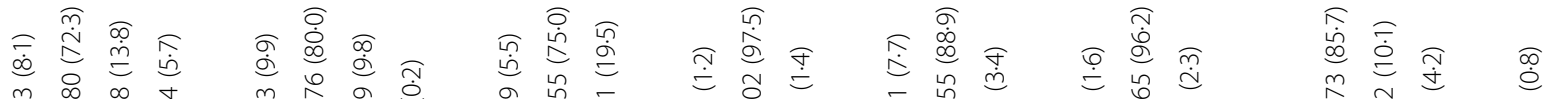

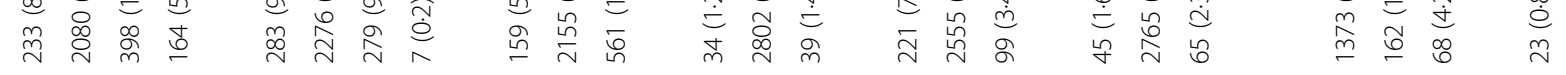

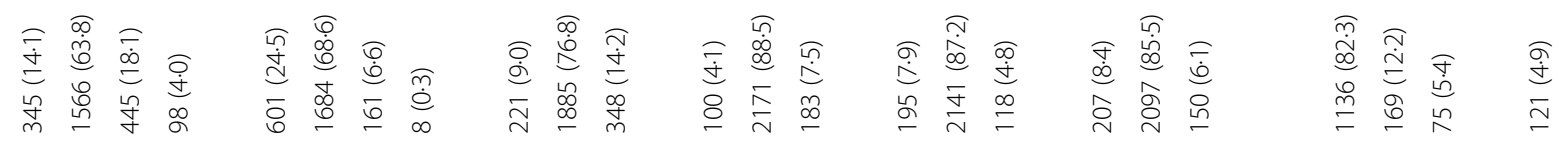

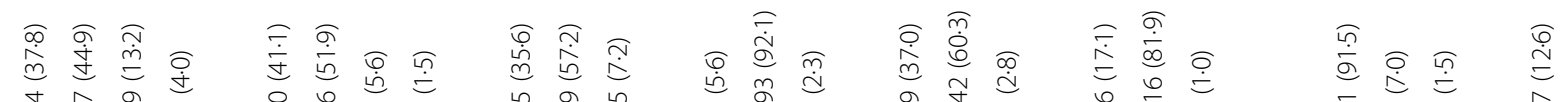

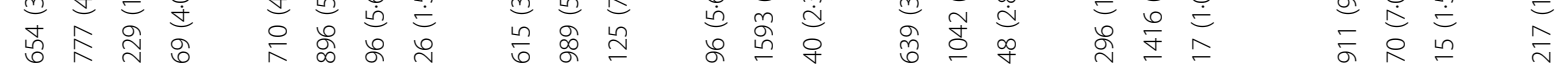

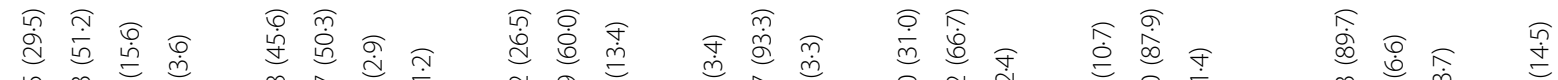

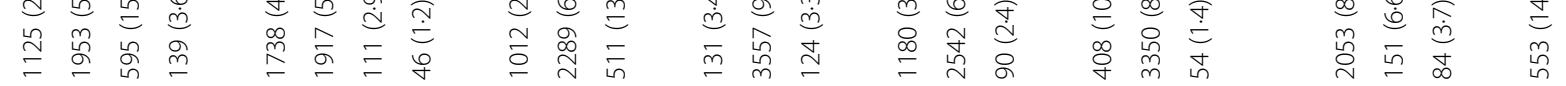

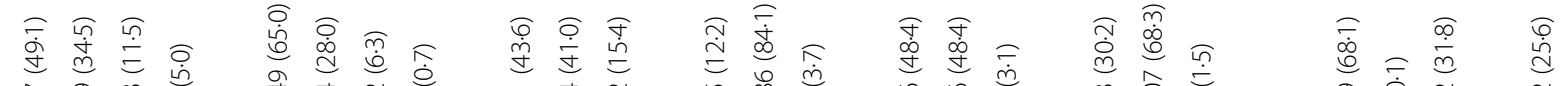

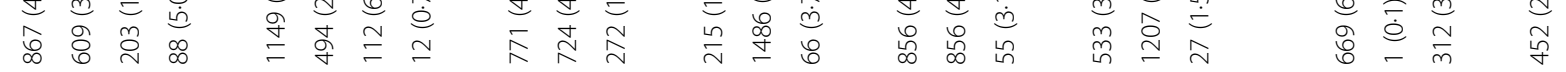

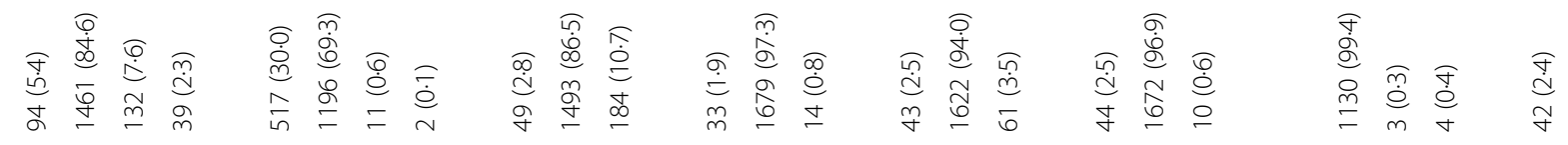

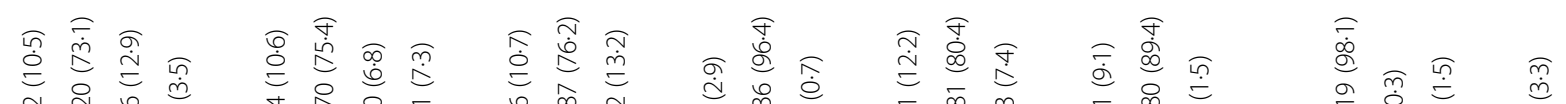

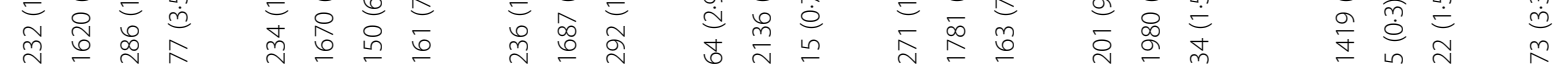

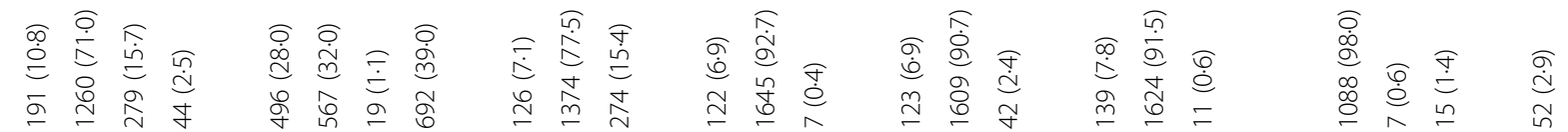

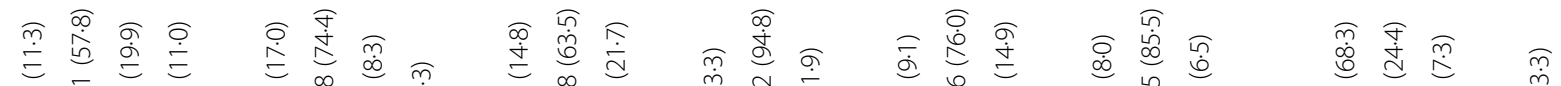

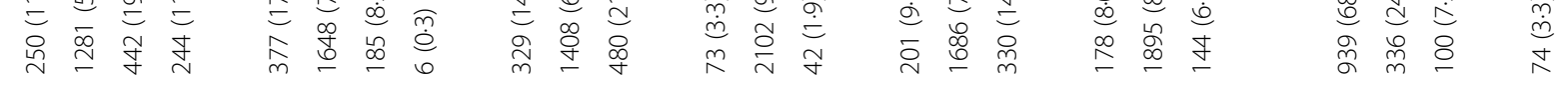

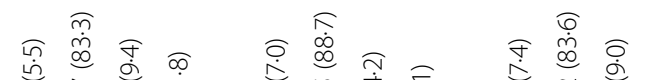

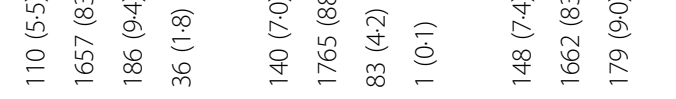
id

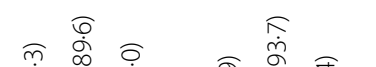
oิ

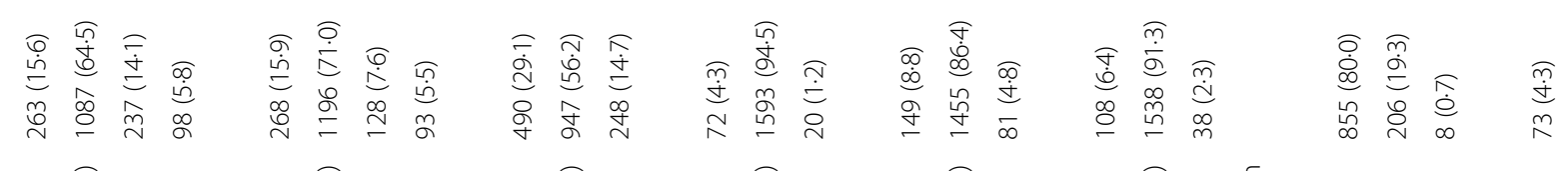

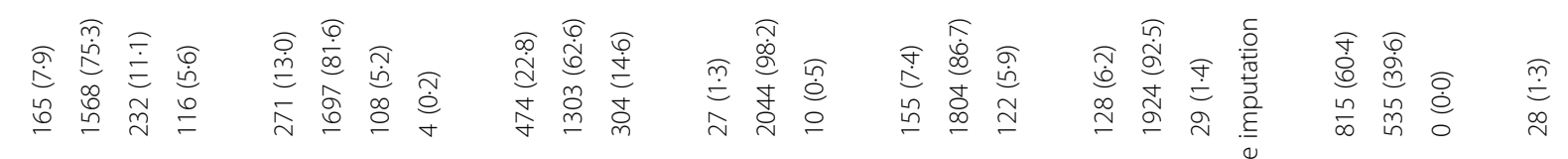




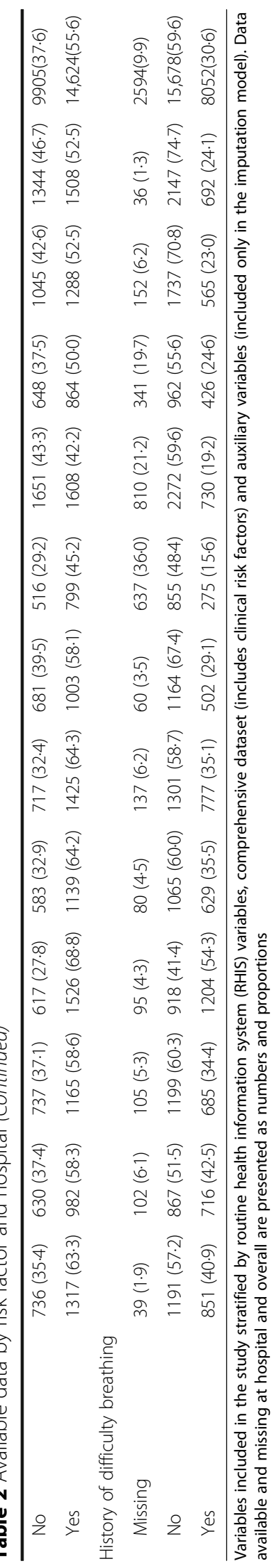




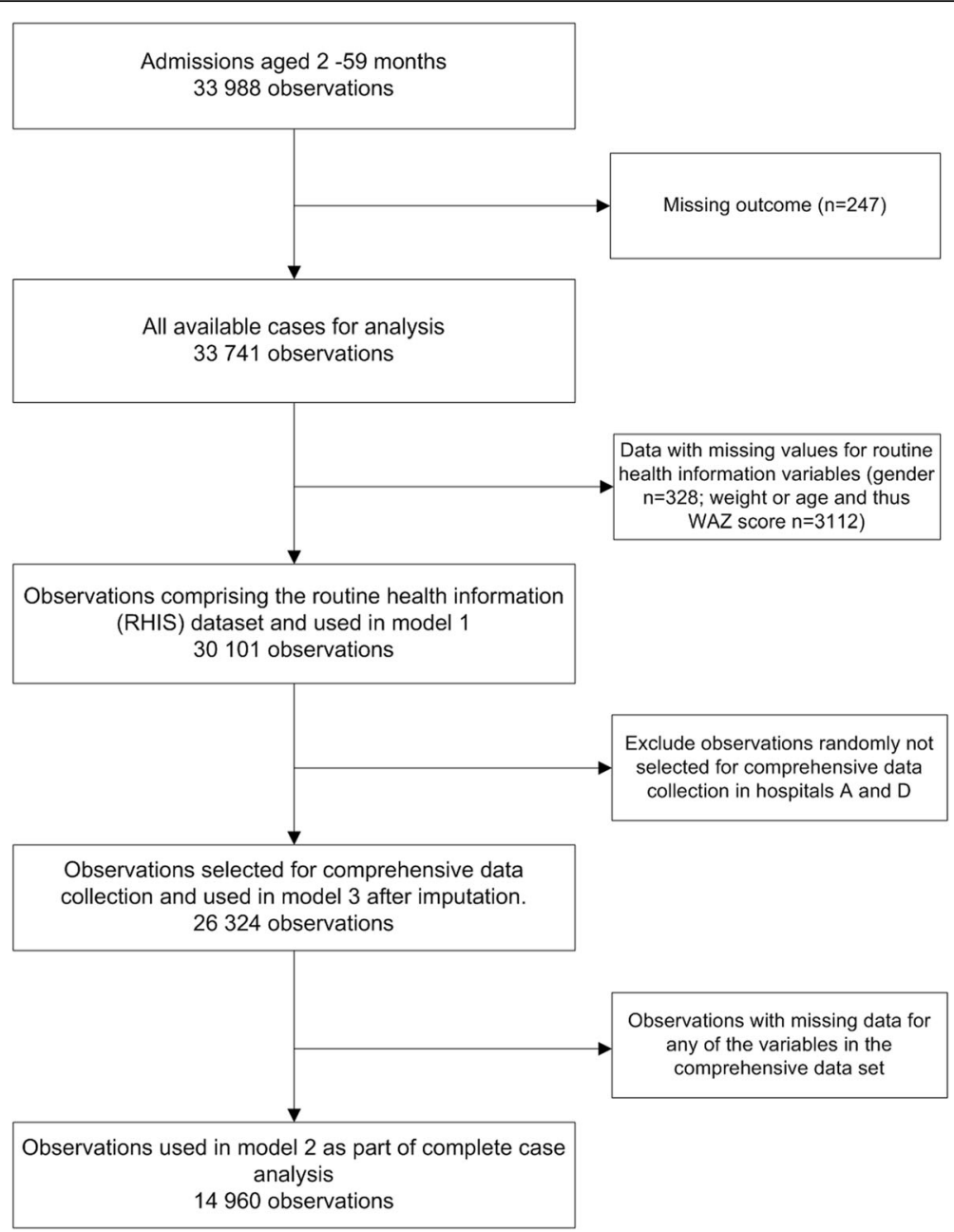

Fig. 2 Availability of data across the different models. Illustrates the number of observations used in each of the models listed

recommended for missing data rates of $10 \%-30 \%$ per variable[24, 25]. All variables in the RHIS and comprehensive datasets and identified interaction terms were included in the imputation procedures. To improve the power of the imputation model, we included auxiliary variables (history of cough and difficulty breathing) which may be clinically useful in diagnosis and are relatively well documented, and a variable denoting use of the paediatric admission record as this improves documentation and may therefore influence missingness [10]. We replicated analyses of associations with mortality including interaction terms after imputation in Model 3 (see Table 3).

In order to assess the plausibility of a MAR mechanism, we performed analysis under a Missing Not At Random (MNAR) assumption using pattern mixture models that included interaction terms. This proceeded as follows; first, we derived three missingness patterns amongst cases in the dataset: no missing data $(57 \%$ cases); minimum 1 to maximum 3 variables per case with missing data (26\% cases); $>3$ variables per case with missing data (17\% cases). We performed multiple imputations and fitted the same multivariable models for each pattern independently. Thereafter, we pooled the estimates across the three patterns weighting by the proportions of individuals in each pattern per variable and compared these results with model 3 estimates estimated under a MAR assumption. We present the results of the MNAR analyses in Appendix.

\section{Panel 3: Sensitivity analyses}

We conducted various sensitivity analyses to explore the consistency of our results under different scenarios. First, we explored associations with mortality using the comprehensive imputed dataset but restricted the analysis to cases with only common childhood illnesses (malaria, pneumonia, diarrhoea/ dehydration, malnutrition, meningitis, anaemia and asthma) to exclude possible effects of uncommon, 
Table 3 Univariable and Multivariable analysis for associations with mortality

\begin{tabular}{|c|c|c|c|c|}
\hline & \multicolumn{2}{|c|}{$\begin{array}{l}\text { Univariable analysis - pooled } \\
\text { data }\end{array}$} & \multirow{2}{*}{$\begin{array}{l}\text { Model } 2 \text { - Mulitvariable model for } \\
\text { associations with mortality for complete } \\
\text { case analysis including interaction terms } \\
\text { for malaria endemicity } \\
\text { OR }(95 \% \mathrm{Cl})\end{array}$} & \multirow{2}{*}{$\begin{array}{l}\text { Model } 3 \text { - Mulitvariable model for } \\
\text { associations with mortality on } \\
\text { imputed data including interaction } \\
\text { terms for malaria endemicity } \\
\text { OR }(95 \% \mathrm{Cl})\end{array}$} \\
\hline & OR $(95 \% \mathrm{Cl})$ & $P$ value & & \\
\hline AUC & & & 0.86 & $0 \cdot 85$ \\
\hline Pseudo R-squared & & & 0.25 & 0.24 \\
\hline \multicolumn{5}{|l|}{ Age group ${ }^{a}$} \\
\hline $2 \_6$ months & ref & & & \\
\hline 7 _ 11 months & $0.72(0.64-0.82)$ & $<0.001$ & & \\
\hline 12_59 months & $0.40(0.36-0.45)$ & & & \\
\hline $\begin{array}{l}\text { 2_6 months in high malaria } \\
\text { prevalence }\end{array}$ & & & ref & ref \\
\hline $\begin{array}{l}7 \text { __1 months in high malaria } \\
\text { prevalence }\end{array}$ & & & $0.46(0.36-0 \cdot 60)$ & $0.43(0.29-0.63)$ \\
\hline $\begin{array}{l}12 \_59 \text { months in high malaria } \\
\text { prevalence }\end{array}$ & & & $0.41(0.33-0.50)$ & $0.37(0 \cdot 27-0.50)$ \\
\hline $\begin{array}{l}7 \text { _ } 11 \text { months in Low malaria } \\
\text { prevalence }\end{array}$ & & & $0.34(0.15-0.75)$ & $0.33(0.19-0.57)$ \\
\hline $\begin{array}{l}\text { 12_59 months in Low malaria } \\
\text { prevalence }\end{array}$ & & & $0.29(0.14-0.62)$ & $0.29(0 \cdot 17-0.49)$ \\
\hline \multicolumn{5}{|l|}{ Child sex } \\
\hline Female & ref & & ref & ref \\
\hline Male & $0.79(0.72-0.86)$ & $<0.001$ & $0.71(0.64-0.80)$ & $0.67(0.57-0.79)$ \\
\hline \multicolumn{5}{|l|}{ WAZ score ${ }^{a}$} \\
\hline 0 or $>=1 S D$ & ref & & & \\
\hline Minus 1 SD & $1 \cdot 35(1 \cdot 17-1 \cdot 56)$ & $<0.001$ & & \\
\hline Minus 2 SD & $2 \cdot 26(1 \cdot 95-2 \cdot 61)$ & & & \\
\hline Minus 3 SD & $4 \cdot 35(3.86-4.92)$ & & & \\
\hline $\begin{array}{l}0 \text { or }>=1 \text { SD in high malaria } \\
\text { prevalence }\end{array}$ & & & ref & ref \\
\hline $\begin{array}{l}\text { Minus } 1 \mathrm{SD} \text { in high malaria } \\
\text { prevalence }\end{array}$ & & & $1.50(1.15-1.95)$ & $1 \cdot 19(0.85-1.67)$ \\
\hline $\begin{array}{l}\text { Minus } 2 \text { SD in high malaria } \\
\text { prevalence }\end{array}$ & & & $1 \cdot 25(0.95-1.65)$ & $1.50(1.03-2 \cdot 17)$ \\
\hline $\begin{array}{l}\text { Minus } 3 \text { SD in high malaria } \\
\text { prevalence }\end{array}$ & & & $2 \cdot 96(2 \cdot 27-3 \cdot 86)$ & $3.01(2 \cdot 09-4 \cdot 35)$ \\
\hline $\begin{array}{l}\text { Minus } 1 \text { SD in Low malaria } \\
\text { prevalence }\end{array}$ & & & $0.93(0.45-1.93)$ & $1.06(0.61-1.82)$ \\
\hline $\begin{array}{l}\text { Minus } 2 \text { SD in Low malaria } \\
\text { prevalence }\end{array}$ & & & $1.17(0.56-2.44)$ & $0.88(0.52-1 \cdot 51)$ \\
\hline $\begin{array}{l}\text { Minus } 3 \text { SD in Low malaria } \\
\text { prevalence }\end{array}$ & & & $2 \cdot 36(1 \cdot 13-4 \cdot 94)$ & $2 \cdot 09(1 \cdot 22-3 \cdot 56)$ \\
\hline \multicolumn{5}{|l|}{ Number of comorbidities } \\
\hline 0 & ref & & ref & ref \\
\hline 1 & $1.44(1.28-1.62)$ & $<0.001$ & $0.99(0.85-1 \cdot 16)$ & $1.08(0.86-1 \cdot 37)$ \\
\hline 2 & $2 \cdot 21(1.94-2 \cdot 50)$ & & $1.03(0.86-1.23)$ & $1 \cdot 27(0.98-1.64)$ \\
\hline$>=3$ & $3 \cdot 67(3 \cdot 18-4 \cdot 23)$ & & $1 \cdot 25(1.02-1 \cdot 55)$ & $1 \cdot 68(1 \cdot 25-2 \cdot 25)$ \\
\hline \multicolumn{5}{|l|}{ History of fever } \\
\hline No & ref & & ref & ref \\
\hline
\end{tabular}


Table 3 Univariable and Multivariable analysis for associations with mortality (Continued)

\begin{tabular}{|c|c|c|c|c|}
\hline Yes & $0.96(0.84-1 \cdot 10)$ & 0.555 & $0.77(0.66-0.90)$ & $0.76(0.62-0.92)$ \\
\hline \multicolumn{5}{|l|}{ History of diarrhoea } \\
\hline No & ref & & ref & ref \\
\hline Yes & $2 \cdot 02(1 \cdot 82-2 \cdot 25)$ & $<0.001$ & $1 \cdot 34(1 \cdot 16-1 \cdot 56)$ & $1 \cdot 45(1 \cdot 20-1 \cdot 76)$ \\
\hline \multicolumn{5}{|l|}{ Convulsions } \\
\hline No & ref & & ref & ref \\
\hline Yes & $1 \cdot 13(1.00-1 \cdot 28)$ & 0.045 & $1.54(1 \cdot 32-1 \cdot 81)$ & $1.35(1.09-1.67)$ \\
\hline \multicolumn{5}{|l|}{ Vomitting everything } \\
\hline No & ref & & ref & ref \\
\hline Yes & $1.41(1.25-1.58)$ & $<0.001$ & $1 \cdot 04(0 \cdot 91-1 \cdot 20)$ & $1.03(0.86-1.24)$ \\
\hline \multicolumn{5}{|l|}{ Indrawing } \\
\hline No & ref & & ref & ref \\
\hline Yes & $2 \cdot 84(2 \cdot 55-3 \cdot 18)$ & $<0.001$ & $2 \cdot 61(2 \cdot 28-2 \cdot 98)$ & $2 \cdot 48(2.08-2.96)$ \\
\hline \multicolumn{5}{|l|}{ Pallor } \\
\hline None & ref & & ref & ref \\
\hline Some/severe & $3.39(3.03-3.79)$ & $<0.001$ & $2 \cdot 21(1.93-2.53)$ & $2 \cdot 32(1 \cdot 92-2 \cdot 81)$ \\
\hline \multicolumn{5}{|l|}{ Central cyanosis } \\
\hline No & ref & & ref & ref \\
\hline Yes & $6 \cdot 36(4.54-8.90)$ & $<0.001$ & $2 \cdot 64(1 \cdot 70-4 \cdot 12)$ & $3.25(1.91-5.53)$ \\
\hline \multicolumn{5}{|l|}{ AVPU } \\
\hline Alert & ref & & ref & ref \\
\hline Not alert (VPU) & $8 \cdot 95(7 \cdot 88-10 \cdot 17)$ & $<0.001$ & $3.98(3 \cdot 31-4 \cdot 77)$ & $3.95(3 \cdot 16-4.95)$ \\
\hline \multicolumn{5}{|l|}{ Ability to drink ${ }^{a}$} \\
\hline No & ref & & & \\
\hline Yes & $0 \cdot 23(0 \cdot 20-0 \cdot 26)$ & $<0.001$ & & \\
\hline $\begin{array}{l}\text { Ability to drink no in high } \\
\text { malaria prevalence }\end{array}$ & & & ref & ref \\
\hline $\begin{array}{l}\text { Ability to drink yes in high } \\
\text { malaria prevalence }\end{array}$ & & & $0.63(0.49-0 \cdot 80)$ & $0.65(0.48-0.87)$ \\
\hline $\begin{array}{l}\text { Ability to drink yes in Low } \\
\text { malaria prevalence }\end{array}$ & & & $0.51(0.24-1.08)$ & $0.44(0.25-0.78)$ \\
\hline \multicolumn{5}{|l|}{ Stiff neck ${ }^{a}$} \\
\hline No/soft & ref & & & \\
\hline Yes & $2 \cdot 71(2 \cdot 13-3 \cdot 44)$ & $<0.001$ & & \\
\hline $\begin{array}{l}\text { Stiff neck no in high malaria } \\
\text { prevalence }\end{array}$ & & & ref & ref \\
\hline $\begin{array}{l}\text { Stiff neck yes in high malaria } \\
\text { prevalence }\end{array}$ & & & $2 \cdot 17(1 \cdot 38-3 \cdot 42)$ & $3.92(2 \cdot 15-7.16)$ \\
\hline $\begin{array}{l}\text { Stiff neck yes in low malaria } \\
\text { prevalence }\end{array}$ & & & $3.07(1 \cdot 28-7 \cdot 36)$ & $1.53(0.81-2.90)$ \\
\hline \multicolumn{5}{|l|}{ Skin pinch } \\
\hline Immediate & ref & & ref & ref \\
\hline $1-2 s$ & $2 \cdot 25(1.96-2.59)$ & $<0.001$ & $1.29(1.09-1.52)$ & $1 \cdot 17(0.94-1.44)$ \\
\hline$>2 \mathrm{~s}$ & $6 \cdot 18(5 \cdot 28-7 \cdot 24)$ & & $1.80(1.43-2 \cdot 26)$ & $1.47(1.09-1.98)$ \\
\hline \multicolumn{5}{|l|}{ Capillary refill time } \\
\hline$<=2 \mathrm{sCs}$ & ref & & ref & ref \\
\hline$>3 \mathrm{~s}$ & $3 \cdot 28(2 \cdot 80-3 \cdot 84)$ & $<0.001$ & $1.46(1.15-1.86)$ & $1 \cdot 68(1 \cdot 32-2 \cdot 13)$ \\
\hline
\end{tabular}


Table 3 Univariable and Multivariable analysis for associations with mortality (Continued)

\begin{tabular}{|c|c|c|c|c|}
\hline Indeterminate & $0.70(0.51-0.97)$ & & $1 \cdot 17(0 \cdot 79-1 \cdot 73)$ & $1.83(1 \cdot 12-2.99)$ \\
\hline \multicolumn{5}{|l|}{ Sunken eyes } \\
\hline No & ref & & ref & ref \\
\hline Yes & $2 \cdot 76(2 \cdot 44-3 \cdot 12)$ & $<0.001$ & $1 \cdot 12(0 \cdot 96-1 \cdot 31)$ & $1 \cdot 24(1.00-1 \cdot 55)$ \\
\hline \multicolumn{5}{|l|}{ Jaundice } \\
\hline None & ref & & ref & ref \\
\hline Moderate/severe & $2 \cdot 03(1.55-2 \cdot 66)$ & $<0.001$ & $1 \cdot 78(1 \cdot 30-2 \cdot 42)$ & $1.64(1.01-2 \cdot 65)$ \\
\hline \multicolumn{5}{|l|}{ Severe wasting ${ }^{a}$} \\
\hline No & ref & & & \\
\hline Yes & $5 \cdot 01(4 \cdot 32-5 \cdot 81)$ & $<0.001$ & & \\
\hline $\begin{array}{l}\text { Severe wasting no in high } \\
\text { malaria prevalence }\end{array}$ & & & ref & ref \\
\hline $\begin{array}{l}\text { Severe wasting yes in high } \\
\text { malaria prevalence }\end{array}$ & & & $2 \cdot 35(1 \cdot 68-3 \cdot 27)$ & $2 \cdot 54(1 \cdot 70-3 \cdot 82)$ \\
\hline $\begin{array}{l}\text { Severe wasting yes in low } \\
\text { malaria prevalence }\end{array}$ & & & $1.99(0.97-4.09)$ & $1.66(0.95-2.87)$ \\
\hline \multicolumn{5}{|l|}{ Oedema of malnutrition ${ }^{a}$} \\
\hline None & ref & & & \\
\hline Moderate/severe & $3.02(2 \cdot 39-3 \cdot 80)$ & $<0.001$ & & \\
\hline $\begin{array}{l}\text { Oedema none in high malaria } \\
\text { prevalence }\end{array}$ & & & ref & ref \\
\hline $\begin{array}{l}\text { Oedema mild/moderate in } \\
\text { high malaria prevalence }\end{array}$ & & & $2 \cdot 66(1.82-3 \cdot 89)$ & $3.13(1.95-5.02)$ \\
\hline $\begin{array}{l}\text { Oedema mild/moderate in } \\
\text { Low malaria prevalence }\end{array}$ & & & $2 \cdot 45(1 \cdot 17-5 \cdot 13)$ & $1.88(1.08-3.25)$ \\
\hline \multicolumn{5}{|l|}{ Malaria endemicity } \\
\hline High & ref & $<0.001$ & ref & ref \\
\hline Low & $0.90(0.83-0.99)$ & & $0.71(0.46-1.08)$ & $0.78(0.43-1.42)$ \\
\hline \multicolumn{5}{|l|}{ Hospital } \\
\hline A & ref & & ref & ref \\
\hline B & $1.23(1.01-1.61)$ & $<0.001$ & $1 \cdot 26(0.91-1 \cdot 73)$ & $1.69(1.04-2.74)$ \\
\hline C & $1.83(1.53-2 \cdot 20)$ & & $1.74(1 \cdot 30-2 \cdot 32)$ & $1.90(1 \cdot 26-2 \cdot 85)$ \\
\hline D & $2 \cdot 46(2 \cdot 04-2 \cdot 96)$ & & $1 \cdot 53(1 \cdot 16-2 \cdot 01)$ & $1.99(1.33-2.98)$ \\
\hline E & $0.53(0.39-0.72)$ & & $0.60(0.40-0.90)$ & $0.53(0.28-1.00)$ \\
\hline $\mathrm{F}$ & $1.00(0.79-1.26)$ & & $0.91(0.66-1.26)$ & $0.88(0.56-1.39)$ \\
\hline G & $0.48(0.34-0.67)$ & & $0.75(0.49-1 \cdot 15)$ & $0.81(0.43-1.50)$ \\
\hline $\mathrm{H}$ & $1 \cdot 41(1 \cdot 14-1 \cdot 76)$ & & $0.83(0 \cdot 62-1 \cdot 11)$ & $0.90(0.52-1.57)$ \\
\hline । & $1.43(1 \cdot 20-1.72)$ & & $1.23(0.98-1.55)$ & $1 \cdot 15(0.82-1.60)$ \\
\hline J & $1.08(0.86-1.37)$ & & $0.68(0.50-0.92)$ & $1.05(0.68-1.63)$ \\
\hline K & $1.52(1.25-1.84)$ & & $0.82(0.64-1.07)$ & $0.95(0.68-1.32)$ \\
\hline L & $1 \cdot 40(1 \cdot 15-1 \cdot 70)$ & & na & na \\
\hline
\end{tabular}

Model 2 results are based on complete case analysis while model 3 results are based on the imputed dataset; both models include interaction terms for malaria prevalence. ${ }^{\mathrm{a}}$ Variables with significant interactions with malaria endemicity

high mortality conditions that might vary across place. Second, we conducted analyses restricted to the 'best months' of data collection by excluding the first 9 months (November 2013 to July 2014) for hospitals I and J and 7 months (February to August 2014) for hospital $\mathrm{H}$ to limit the scale of imputation. Third, we undertook analyses for data stratified according to whether cases were in high or low admission seasons. The estimates for associations between risk factors and mortality from these sensitivity analyses were 
clinically not appreciably different from those reported for Model 3 (data available on request).

Calibration and discrimination of the models was assessed using pseudo R-squared and area under the receiver operating curve (AUC) measures. Results from the univariable and multivariable analyses are reported as crude and adjusted odds ratios respectively with corresponding 95\% confidence intervals (CIs) adjusted for clustering within hospitals. All analyses were undertaken using Stata v13 (StataCorp, Texas, USA).

\section{Results}

A total of 44,314 children were admitted into the CIN hospitals from September 2013 to March 2015, of these 33,741 (76\%) were aged 2-59 months, had outcome data and a plausible date of admission or death. Characteristics of children by hospital and overall are presented in Table 2 . The overall cluster adjusted crude mortality across hospitals was $6.2 \%$ (95\% CI 4.9 to 7.8 ; range $2.1 \%$ - $11.0 \%$ ) with five-fold variation across hospitals while the risk- adjusted mortality rate derived from Model 3 was 6.2\% (95\% CI 4.7 to 7.6; range 3.0\% - 9.4\%) (Fig. 3a). Hospital identity was significantly associated with mortality (likelihood ration test, LRT $<0.001$ when compared to the null model). The distribution of risk factors per admission varied by hospital and outcome with $85 \%$ of children who survived having 3 or fewer risk factors while of those who died 53\% had more than 3 risk factors (see Fig. 3b).

The amount of missing data varied by variable and hospital (see Table 2 and panel 2). Pooled estimates of association weighted by proportion across missingness patterns were similar to those from model 3 (imputed data assuming MAR) and are presented in Appendix. These findings provide support for assuming that data were missing at random.

\section{Clinical risk factors for mortality}

All characteristics included in the RHIS dataset, derived covariables and all primary symptoms and signs included in the comprehensive data were significantly associated with mortality in univariable analyses except history of

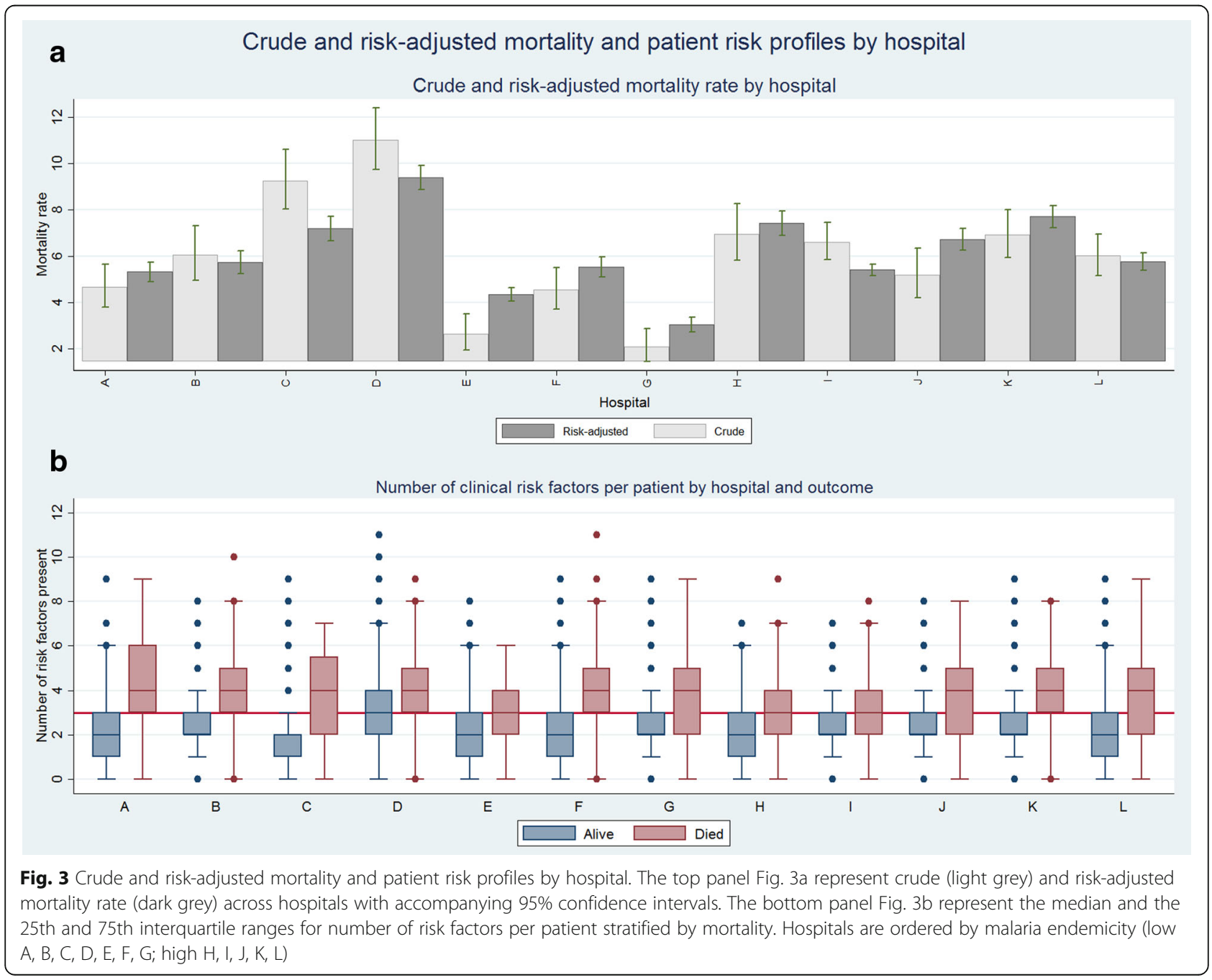


fever with anticipated (Table 3) direction of effect. Although we utilised alert vs not alert in risk adjustment exploratory univariable analysis illustrated an increasing risk of mortality with a decreasing conscious level; with alert as the reference category risks were V OR 4.61; 95\% CI 3.54-6.00, P OR 9.31; 95\% CI 7.84-11.05 and U OR 17.59; 95\% 13.42-23.04.

Multivariable model 1, using RHIS data had an AUC of 0.73 and pseudo- $R^{2}$ of 0.09 suggesting poor to modest model fit (assuming a cut off for good model fit for pseudo- $R^{2}$ of 0.20 and above [26]) and that they are not likely to be suitable for understanding hospital populations' risk of mortality. The complete case analysis model (model 2) and analyses after imputation (model 3 ), including malaria prevalence interactions, had better model fit (pseudo- $\mathrm{R}^{2}$ of 0.25 ; AUC of 0.86 and pseudo$\mathrm{R}^{2}$ of 0.24; AUC of 0.85 respectively).

Estimates of association from complete case analysis and data sets using all admissions after imputation were similar in magnitude and direction of effect across all the clinical risk factors and we therefore present results from model 3 using imputed data as this makes maximum use of available data. These analyses (Table 3) show in all cases where interactions were not found that risk factors remained significantly associated with mortality except vomiting everything and number of comorbidities. Male gender (OR 0.67; 95\% CI 0.57-0.79) and history of fever (OR 0.76 ; 95\% CI $0.62-0.92$ ) were associated with protection while reduced conscious level was strongly associated with mortality (OR 3.95; 95\% CI 3.16-4.95). Tests for interactions between risk factors and malaria prevalence were significant for ability to drink, stiff neck, severe wasting, oedema, age group and weight-for-age z-score.

For covariables with significant interactions, estimates of association for having a stiff neck and severe wasting in low malaria prevalence hospitals had consistent but lower magnitude directions of effect than in high malaria prevalence areas (OR 1.53; 95\% CI 0.81 to 2.90 vs $3.92 ; 95 \%$ CI 2.15 to 7.16 and OR 1.66 ; $95 \%$ CI 0.95 to 2.87 vs OR 2.54; 95\% CI 1.70-3.82 respectively) and were not significant (Table 3) perhaps reflecting a loss of power (see Table 2). The estimates of association for being able to drink, oedema of malnutrition and age group remained significant in both malaria prevalence settings with consistently lower magnitudes of association in low malaria prevalence settings (OR, 0.65 vs $0.44,3.13$ vs 1.88 , and 0.43 vs 0.33 (7-11 months) and 0.37 vs 0.29 (12-59 months) respectively). For weight-for-age $\mathrm{z}$-score the estimate of effect was also attenuated in the low malaria prevalence hospitals (OR 2.09; 95\% CI 1.22-3.56 vs OR 3.01; 95\% CI 2.094.35). Signs associated with dehydration were consistently associated with mortality. For three hospitals (B, C and D) a persistent association with mortality was observed within these multivariable models (ORs 1.69, 1.90 and 1.99 respectively, Table 3 ).

\section{Discussion}

All-cause mortality is highly variable across only 12 hospitals even within a common age group. Variation in mortality was associated with the proportion of children with multiple risk factors, something that cannot be determined using data from existing routine health information systems. This variation in risk factors at presentation might be linked to the varying number of comorbidities at presentation resulting from overlapping syndromic diagnoses. This finding of major variation in the risk profile of children admitted to hospitals is important but rarely highlighted in existing research literature from low-income settings. The variation of mortality with hospital identity is probably explained by associated variability in underlying risk factors (such as malaria and HIV prevalence, socio-economic status, nutrition and access) that influence case-mix and caseseverity. Although, these data exist at a population level, adjusting for these parameters would require a large number of hospitals in more defined, smaller regions. As such we have refrained from adjusting for these parameters in our models due to the risk of ecological fallacy where population estimates do not necessarily apply to the population seeking care. In addition, care seeking patterns in Kenya vary across populations and individuals with some of the patients accessing care directly from hospital while others are through referral from primary health care services but these data are rarely documented and hence difficult to disentangle within this population. Thus, although there is a standard policy guiding the provision of $\mathrm{PHC}$ in Kenya and how patients might progress through the system anecdotal evidence suggests procedures are rarely followed in practice and there are limited data from primary care on access and care seeking behaviors.

Mortality may also potentially be influenced by differing availability of resources across hospitals and variation in care practices shown to exist in other studies [27, 28]. More comprehensive datasets from a larger number of hospitals, as are being used in high income settings [29, 30], would however be required to try and determine the degree to which quality of care and local context are associated with inpatient mortality in low-income settings. Even then the use of mortality to infer anything about quality of care specifically is contested $[1,31]$. What is more pertinent to low-income contexts is that such variation in mortality should prompt thinking on where system strengthening efforts may be most needed.

In the multivariable analyses, we demonstrate that majority of clinical risk factors included in best-practice guidelines were associated with mortality irrespective of diagnosis. This approach is important due to the inability to confirm diagnoses in these settings. For example, 
we have previously reported that basic investigations like blood culture, CSF analysis and urine culture are not routinely available [28] and there is no access to tests of inflammatory markers, for biochemical derangements or for detection of other pathogens except for malaria and HIV. Thus, an approach that is agnostic of diagnosis may be the more useful approach at scale. Prior demonstrations of association are typically from single sites or focus on specific diseases $[15,16,19,32]$. We believe this is the first report of the value of these clinical risk factors from multiple settings, across all cause admissions, with routine observations made by large numbers of clinicians. As malaria prevalence and other attributes of the hospitals' setting may be correlated, including for example proportion living in poverty and hospital size, we cannot attribute the influence of malaria prevalence on the behaviour of risk factors to malaria as a disease. However, findings suggest that future efforts to explore variability in mortality or develop risk prediction approaches should take the prevalence of malaria into account.

Our data support the practical, day to day use of these clinical factors in identifying children who may be prioritised for attention, specific treatments and review. Integrating such clinical factors into a low-income setting, patient-level prognostic score might be possible [16] replicating approaches in high-income settings [33]. However, the implementation of such scores in routine settings with limited human resources, high staff turnover and without computer assisted decision support would likely be very challenging as even basic job aides are somewhat slowly adopted [28]. These clinical features might however be used to characterise risk profiles of hospital populations aged 2 to 59 months. This might enable improved understanding of changes in mortality over time within sites using methods such as cumulative sum control charts (CUSUM) [34-37] where riskadjustment may facilitate exploration of variation in a single institution's performance [1,3,31]. More pragmatically such risk profiles may help point to different health system challenges. High prevalence of cases with high risk factor density may suggest problems of access, late detection or delayed referral. They may also point to particularly vulnerable populations within catchment areas, where malnutrition and poverty are prevalent for example, or demonstrate the impact of varying disease ecology that should be taken into account in resource allocation. Our findings suggest that existing routine health information systems data (such as DHIS2) [38] would be inadequate for this purpose, suggesting value in developing and implementing suitable common data frameworks.

The data we report need to be interpreted in the light of their limitations. First, is the missing data problem commonly associated with collecting data in routine settings. The Clinical Information Network worked with hospitals to promote data quality that improved over time but missingness varied across variables and hospitals. Thus, just less than $60 \%$ of cases were included in our complete case multivariable models. We used multiple imputation to allow use of all available data and undertook sensitivity analyses that suggest our findings are generally robust. An alternative approach would be using Expectation-Maximization (EM) algorithms to get maximum likelihood estimates [39]. Second, our sample of hospitals is small and non-random, with selection based on feasibility and efforts to represent diverse but not all epidemiological and socio-cultural contexts. One hospital that failed to provide reasonable quality data was excluded from these analyses. As such, due to the limited number of hospitals, our models did not sufficient power to explore potentially important factors at the hospital level. Thirdly, diagnoses are clinical and rarely informed by diagnostics while risk factors such as hypoglycaemia, hypoxemia or an individual's HIV status could not be examined as these are rarely routinely evaluated. Fourth, we did not include more robust nutritional indicators like mid-upper arm circumference or weight-for-height $\mathrm{z}$ scores or account for vaccination status which may influence mortality because such data are largely missing. However, there is evidence that vaccination coverage is high in Kenya and we were able to use weight-for-age $\mathrm{z}$ scores for nutritional assessment.

\section{Conclusion}

In summary, all-cause crude and cluster adjusted mortality rate was highly variable across hospitals. Such variation is largely explained by variation in severity of illness at the time of clinical presentation, findings that point to underlying differences in population health and health system performance that will need to be explored. Our data supports the use of clinical risk factors drawn from guidelines in day-to-day use in prioritizing care and identifying children at the highest risk of death but also to develop risk adjusted mortality estimates across hospitals. We also demonstrate how having a large patient level dataset from multiple geographically diverse sites may improve our understanding of health system challenges and performance. Such work provides a learning platform for the design of common data frameworks that are relevant to clinical practice and might be incorporated into future electronic medical records (EMRs) that go beyond a focus on costaccounting needs [40]. To maximise the future value of EMRs there is a clear imperative for researchers, clinicians, policy makers and health care managers to engage in their design so they enable health system performance monitoring at scale as is occurring in specific fields such as HIV care [41, 42]. 


\section{Appendix}

Table 4 Sensitivity analysis for imputation based on the MAR versus MNAR assumption high malaria prevalence strata

\begin{tabular}{|c|c|c|c|c|c|c|}
\hline & & $\begin{array}{l}\text { Variables with } \\
\text { no missing data }\end{array}$ & $\begin{array}{l}1-3 \text { variables } \\
\text { with missing } \\
\text { data }\end{array}$ & $\begin{array}{l}4 \text { or more } \\
\text { variables with } \\
\text { missing data }\end{array}$ & $\begin{array}{l}\text { Mantel Haenszel } \\
\text { estimates weighted } \\
\text { across missing patterns } \\
\text { (MNAR) }\end{array}$ & $\begin{array}{l}\text { Model } 3 \text { - Mulitvariable } \\
\text { model for associations } \\
\text { with mortality on } \\
\text { imputed data including } \\
\text { interaction terms for } \\
\text { malaria endemicity } \\
\text { (MAR) }\end{array}$ \\
\hline & & OR (95\% Cl) & OR (95\% Cl) & OR (95\% Cl) & OR (95\% Cl) & OR (95\% Cl) \\
\hline \multicolumn{7}{|l|}{ Age group $^{a}$} \\
\hline & $\begin{array}{l}\text { 2_6 months and high } \\
\text { malaria prevalence }\end{array}$ & ref & ref & ref & ref & ref \\
\hline & $\begin{array}{l}7 \text { _ } 11 \text { months in high } \\
\text { malaria prevalence }\end{array}$ & $0.43(0.29-0.63)$ & $0.48(0.27-0.86)$ & $0.47(0.29-0.77)$ & $0.48(0.28-0.81)$ & $0.43(0.29-0.63)$ \\
\hline & $\begin{array}{l}\text { 12_59 months in high } \\
\text { malaria prevalence }\end{array}$ & $0.37(0.27-0.5)$ & $0.53(0.34-0.84)$ & $0.35(0.23-0.54)$ & $0.37(0.26-0.51)$ & $0.37(0.27-0.50)$ \\
\hline & $\begin{array}{l}7 \text { _ } 11 \text { months in Low } \\
\text { malaria prevalence }\end{array}$ & $0.34(0.15-0.75)$ & $0.54(0.17-1 \cdot 68)$ & $0.09(0.02-0.35)$ & $0.41(0.14-1.21)$ & $0.33(0.19-0.57)$ \\
\hline & $\begin{array}{l}\text { 12_59 months in Low } \\
\text { malaria prevalence }\end{array}$ & $0.29(\cdot \cdot 14-62)$ & $0.59(0.21-1.72)$ & $0.07(0.02-0.25)$ & $0.39(0.15-1.07)$ & $0.29(0.17-0.49)$ \\
\hline \multicolumn{7}{|l|}{ Child sex } \\
\hline & Female & ref & ref & ref & ref & ref \\
\hline & Male & $0.67(0.57-0.79)$ & $0.7(0.56-0.88)$ & $0.82(0.63-1.05)$ & $0.71(0.58-0.87)$ & $0.67(0.57-0.79)$ \\
\hline \multicolumn{7}{|l|}{ WAZ score ${ }^{a}$} \\
\hline & $\begin{array}{l}0 \text { or }>=1 S D \text { in high } \\
\text { malaria prevalence }\end{array}$ & ref & ref & ref & ref & ref \\
\hline & $\begin{array}{l}\text { Minus } 1 \mathrm{SD} \text { in high } \\
\text { malaria prevalence }\end{array}$ & $1 \cdot 19(0.85-1.67)$ & $1.96(1.25-3.09)$ & $1.54(0.91-2.58)$ & $1.46(0.96-2.23)$ & $1 \cdot 19(0.85-1.67)$ \\
\hline & $\begin{array}{l}\text { Minus } 2 \text { SD in high } \\
\text { malaria prevalence }\end{array}$ & $1.50(1.03-2.17)$ & $1.43(0.81-2.54)$ & $0.89(0.47-1.7)$ & $1 \cdot 29(0 \cdot 79-2 \cdot 12)$ & $1.50(1.03-2.17)$ \\
\hline & $\begin{array}{l}\text { Minus } 3 \mathrm{SD} \text { in high } \\
\text { malaria prevalence }\end{array}$ & $3.01(2.09-4.35)$ & $5 \cdot 23(3 \cdot 21-8 \cdot 54)$ & $1.76(0.95-3.25)$ & $3 \cdot 20(2 \cdot 10-4 \cdot 91)$ & $3.01(2 \cdot 09-4.35)$ \\
\hline & $\begin{array}{l}\text { Minus } 1 \text { SD in Low } \\
\text { malaria prevalence }\end{array}$ & $0.93(.45-1.94)$ & $2 \cdot 20(0 \cdot 8-6 \cdot 01)$ & $0.29(0.07-1 \cdot 18)$ & $1 \cdot 20(0.50-2 \cdot 95)$ & $1.06(0.61-1 \cdot 82)$ \\
\hline & $\begin{array}{l}\text { Minus } 2 \text { SD in Low } \\
\text { malaria prevalence }\end{array}$ & $1 \cdot 17(\cdot 56-2 \cdot 44)$ & $1.61(0.55-4.69)$ & $0 \cdot 17(.04-0.67)$ & $1 \cdot 18(0 \cdot 50-2 \cdot 83)$ & $0.88(0.52-1.51)$ \\
\hline & $\begin{array}{l}\text { Minus } 3 \text { SD in Low } \\
\text { malaria prevalence }\end{array}$ & $2 \cdot 36(1 \cdot 13-4 \cdot 94)$ & $5.85(2.07-16.53)$ & $0.33(0.08-1.33)$ & $3.06(1 \cdot 26-7 \cdot 65)$ & $2 \cdot 09(1 \cdot 22-3 \cdot 56)$ \\
\hline \multicolumn{7}{|c|}{$\begin{array}{l}\text { Number of } \\
\text { comorbidities }\end{array}$} \\
\hline & 0 & ref & ref & ref & ref & ref \\
\hline & 1 & $1.08(0 \cdot 86-1 \cdot 37)$ & $1.21(0.89-1.65)$ & $0.78(0.57-1.08)$ & $0.98(0 \cdot 75-1 \cdot 28)$ & $1 \cdot 08(0 \cdot 86-1 \cdot 37)$ \\
\hline & 2 & $1 \cdot 27(0.98-1.64)$ & $1 \cdot 26(0 \cdot 89-1 \cdot 79)$ & $0.67(0.45-0.99)$ & $1 \cdot 19(0 \cdot 88-1 \cdot 62)$ & $1 \cdot 27(0.98-1 \cdot 64)$ \\
\hline & $>=3$ & $1 \cdot 68(1 \cdot 25-2 \cdot 25)$ & $1 \cdot 22(0.78-1.89)$ & $0.92(0.56-1.53)$ & $1 \cdot 20(0.80-1.82)$ & $1 \cdot 68(1 \cdot 25-2 \cdot 25)$ \\
\hline \multicolumn{7}{|l|}{$\begin{array}{l}\text { History of } \\
\text { fever }\end{array}$} \\
\hline & No & ref & ref & ref & ref & ref \\
\hline & Yes & $0.76(0.62-0.92)$ & $0.79(0.6-1.05)$ & $0.76(0.5-1 \cdot 17)$ & $0.77(0.59-1.00)$ & $0.76(0.62-0.92)$ \\
\hline \multicolumn{7}{|l|}{$\begin{array}{l}\text { History of } \\
\text { diarrhoea }\end{array}$} \\
\hline & No & ref & ref & ref & ref & ref \\
\hline & Yes & $1.45(1 \cdot 2-1 \cdot 76)$ & $1.05(0.8-1.39)$ & $1 \cdot 36(0.92-2)$ & $1.32(1.02-1.71)$ & $1.45(1 \cdot 20-1 \cdot 76)$ \\
\hline
\end{tabular}


Table 4 Sensitivity analysis for imputation based on the MAR versus MNAR assumption high malaria prevalence strata (Continued)

convulsions

No

Yes

ref

$1 \cdot 35(1.09-1 \cdot 67)$

ref

1.73(1.29-2.33)

ref

$1.67(1 \cdot 13-2 \cdot 47)$

ref

ref

Vomitting

everything

\section{No}

Yes

Indrawing

No

Yes

Pallor

None

Some/severe

Central

cyanosis

No

Yes

AVPU

$$
\text { Alert }
$$

Not alert (VPU)

Ability to

drink $^{\mathrm{a}}$

Ability to drink no in high malaria prevalence

Ability to drink yes in high malaria prevalence

Ability to drink yes in Low malaria prevalence ref

$1.03(0.86-1.24)$

ref

2.48(2.08-2.96)

ref

2.91(2.27-3.73)

ref

2.22(1.71-2.87)

2.32(1.92-2.81)

ref

$3.25(1.91-5.53)$

ref

$2 \cdot 37(1 \cdot 1-5 \cdot 11)$

ref

2.3(0.52-10.21)

ref

$2.77(1 \cdot 36-6.33)$

ref

ref

3.95(3.16-4.95)

ref

3.94(2.87-5.41)

4.42(2.53-7.73)

ref

4.06(2.93-5.73)

ref

$0.76(0.5-1 \cdot 15)$

$0.65(0.48-0.87)$

$0.51(0.24-1.08)$

$0.85(0.31-2 \cdot 34)$

ref

$0.58(0.33-1.01)$

ref

$0.66(0 \cdot 45-0.98)$

$0.57(0.23-1.43)$

$0.11(0.02-0.48)$

ref

$2 \cdot 70(1 \cdot 36-5 \cdot 49)$

$2 \cdot 52(0.97-6.81)$

$3.07(1 \cdot 31-7.17)$

Stiff neck yes in low malaria prevalence

Skin pinch

Immediate
$1-2 \mathrm{~s}$
$>2 \mathrm{~s}$

ref

$1 \cdot 17(0.94-1.44)$

1.47(1.09-1.98)

Capillary refill time

$<=2 \mathrm{scs}$
$>3 \mathrm{~s}$

Indeterminate

Sunken eyes

1.26(0.83-1.93) ref

$1.68(1.32-2 \cdot 13)$

$1.83(1.12-2.99)$

ref

$1 \cdot 24(1-1.55)$ ref

$1 \cdot 5(1 \cdot 12-2 \cdot 02)$

2.54(1.67-3.86) ref

$0.96(0.69-1.34)$ ref

ref

1.29(0.99-1.69)

1.96(1.25-3.15)

$2 \cdot 28(1 \cdot 16-4 \cdot 46)$

ref

$1.41(0.85-2.32)$

ref

1.39(0.95-2.07)

1.27(0.51-1.75)

1.68(1.32-2.13)

$1.01(0.43-2.35)$

na

ref

ref

ref

1.24(1.00-1.55) 
Table 4 Sensitivity analysis for imputation based on the MAR versus MNAR assumption high malaria prevalence strata (Continued)

\begin{tabular}{|c|c|c|c|c|c|c|}
\hline \multicolumn{7}{|l|}{ Jaundice } \\
\hline & None & ref & ref & ref & ref & ref \\
\hline & Moderate/severe & $1 \cdot 64(1 \cdot 01-2 \cdot 65)$ & $1 \cdot 72(0 \cdot 96-3 \cdot 1)$ & $1 \cdot 78(0 \cdot 97-3 \cdot 27)$ & $1.71(0.98-2 \cdot 98)$ & $1 \cdot 64(1.01-2 \cdot 65)$ \\
\hline \multicolumn{7}{|l|}{$\begin{array}{l}\text { Severe } \\
\text { wasting }^{a}\end{array}$} \\
\hline & $\begin{array}{l}\text { Severe wasting no in } \\
\text { high malaria prevalence }\end{array}$ & ref & ref & ref & ref & ref \\
\hline & $\begin{array}{l}\text { Severe wasting yes in } \\
\text { high malaria prevalence }\end{array}$ & $2 \cdot 54(1 \cdot 7-3 \cdot 82)$ & $2 \cdot 41(1 \cdot 27-4.58)$ & $2 \cdot 39(1 \cdot 23-4 \cdot 62)$ & $2 \cdot 46(1 \cdot 44-4 \cdot 26)$ & $2 \cdot 54(1 \cdot 70-3 \cdot 82)$ \\
\hline & $\begin{array}{l}\text { Severe wasting yes in } \\
\text { low malaria prevalence }\end{array}$ & $2 \cdot 45(1 \cdot 17-5 \cdot 13)$ & $3 \cdot 27(1 \cdot 09-9.79)$ & $0.32(0.08-1.27)$ & $2 \cdot 29(0 \cdot 94-5 \cdot 79)$ & $1.66(0.95-2 \cdot 87)$ \\
\hline \multicolumn{7}{|c|}{$\begin{array}{l}\text { Oedema of } \\
\text { malnutrition }^{a}\end{array}$} \\
\hline & $\begin{array}{l}\text { Oedema none in high } \\
\text { malaria prevalence }\end{array}$ & ref & ref & ref & ref & ref \\
\hline & $\begin{array}{l}\text { Oedema mild/moderate } \\
\text { in high malaria } \\
\text { prevalence }\end{array}$ & $3.13(1.95-5.02)$ & $2.92(1.44-5.92)$ & $1 \cdot 66(0.67-4.13)$ & $2 \cdot 78(1 \cdot 55-5 \cdot 10)$ & $3.13(1.95-5.02)$ \\
\hline & $\begin{array}{l}\text { Oedema mild/moderate } \\
\text { in Low malaria } \\
\text { prevalence }\end{array}$ & $1.94(0.96-3.90)$ & $2 \cdot 70(0.98-7.47)$ & $0.45(0.11-1.91)$ & $2.02(0.88-4.81)$ & $1.88(1.08-3.25)$ \\
\hline \multicolumn{7}{|c|}{$\begin{array}{l}\text { Malaria } \\
\text { endemicity }\end{array}$} \\
\hline & High & ref & ref & ref & ref & ref \\
\hline & Low & $0.78(0.43-1.42)$ & $1 \cdot 12(0.49-2 \cdot 53)$ & $0.19(0.06-0.63)$ & $0.76(0 \cdot 38-1.58)$ & $0.78(0.43-1.42)$ \\
\hline
\end{tabular}

Model 3 stratified by number of missing variables and weighted estimates across the missing patterns (assumes MNAR) compared to pooled model 3 data (assumes MAR)

${ }^{a}$ Variables with significant interactions with malaria endemicity

\section{Abbreviations}

AUC: Area under the receiver operating curve; CIN: Clinical information network; CUSUM: Cumulative sum control charts; DHIS2: District Health Information system; EMR: Electronic medical records; KEMRI: Kenya Medical Research Institute; LRT: Likelihood ratio test; MAR: Missing at random; MNAR: Missing Not At Random; PAR: Pediatric admission record; PCV: Pneumococcal conjugate vaccine; REDCap: Research electronic data capture; RHIS: Routine health information system (RHIS; WAZ: Weight-for-age z-score; WHO: World Health Organization

\section{Acknowledgements}

We would like to thank the Ministry of Health who gave permission for this work to be developed and have supported the implementation of the CIN together with the county health executives and all hospital management teams. Collaboration with officers from the Ministry of Health's national Health Management Information System, the Monitoring and Evaluation Unit and the Maternal, Neonatal, Child and Adolescent Health Unit has been important to the initiation of the CIN. We are grateful to the Kenya Paediatric Association for promoting the aims of the CIN and the support they provide through their officers and membership. We also thank the hospital paediatricians and clinical teams on all the paediatric wards who provide care to the children for whom this project is designed. This work is also published with the permission of the Director of KEMRI.

The Clinical Information Network members who contributed to to the design of the data collection tools conduct of the work, collection of data and data quality assurance that form the basis of this report and who saw and approved the report's findings include:David Githanga, Fred Were, Barnabas Kigen, Samuel NgarNgar, Nick Aduro, Rachel Inginia, Beatrice Mutai, Grace Ochieng, Lydia Thuranira, Francis Kanyingi, Margaret Kuria, Sam Otido, Kigondu Rutha, Peris Njiiri, Martin Chabi, Charles Nzioki, Joan Ondere, Caren Emadau, Cecelia Mutiso, Naomi Muinga, Michael Bitok, Timothy Tuti, Boniface Makone, Wycliffe Nyachiro, George Mbevi, Thomas Julius, Susan Gachau and Morris Ogero. David Gathara had full access to all the data in the study and takes responsibility for the integrity of the data and the accuracy of the data analysis.

\section{Funding}

This work was supported by funds from a Senior Research Fellowship awarded to ME by The Wellcome Trust (\#097170). Additional funds from a Wellcome Trust Strategic Award (\#084538) and a Wellcome Trust core grant awarded to the KEMRI-Wellcome Trust Research Programme (\#092654) supported DG and the contribution of EA. The funders had no role in drafting nor the decision for submitting this manuscript.

\section{Availability of data and material}

All summary data underlying the findings is freely available in the manuscript and supplemental files, however since this was data collected in collaboration with the Ministry of Health and under terms of ethical approval granted by KEMRI (SSC Number 2465) and the Ministry of Health. The existing ethical approval and agreements with the Ministry of Health do not provide for the data set to be hosted in a public repository. Access to these raw data may require additional approval from the Ministry of Health and submission of a proposal for ethical review. Requests can be facilitated by contacting the corresponding author (dgathara@kemri-wellcome.org).

\section{Authors' contributions}

The roles of the contributors were as follows: DG and ME conceived the idea of the analyses and DG took primary responsibility for and conducted the analyses with support from LM, PA, SK, GI, RN, EA, MvHB and ME. DG drafted the initial manuscript with support from ME and feedback on drafts was provided by all authors. All authors read and approved the final manuscript.

\section{Consent for publication}

Not applicable 


\section{Competing interests}

The authors declare that they have no competing interests.

\section{Ethics approval and consent to participate}

Scientific and ethical approval for the study which is based on de-identified data collected retrospectively from case records was obtained from the Kenya Medical Research Institute (SSC number 2465). Individual informed consent was not deemed necessary as the study was based on routine de-identified data. The Ministry of Health also gave permission for the study and hospital management teams provided their assent prior to data collection.

\section{Publisher's Note}

Springer Nature remains neutral with regard to jurisdictional claims in published maps and institutional affiliations.

\section{Author details}

${ }^{1}$ Department of Public Health Research, KEMRI Wellcome Trust Research Programme, P.O. Box 43640 00100, Nairobi, Kenya. ${ }^{2}$ Nuffield Department of Medicine, University of Oxford, Oxford OX3 7BN, UK. ${ }^{3}$ Division of Maternal, Newborn, Child and Adolescent Health, Ministry of Health, Nairobi, Kenya. ${ }^{4}$ Department of Paediatrics and Child Health, University of Nairobi, Nairobi 19676-00202, Kenya. ${ }^{5}$ Department of Global Health, Academic Medical Centre, University of Amsterdam, Amsterdam 22700 1100, DE, The Netherlands. ${ }^{6}$ Department of Medical Statistics, London School of Hygiene and Tropical Medicine, London WC1E 7HT, UK.

Received: 28 November 2015 Accepted: 25 March 2017

Published online: 05 April 2017

\section{References}

1. Lilford R, Pronovost P. Using hospital mortality rates to judge hospital performance: a bad idea that just won't go away. BMJ. 2010;340:c2016.

2. Lilford R, Mohammed MA, Spiegelhalter D, Thomson R. Use and misuse of process and outcome data in managing performance of acute medical care : avoiding institutional stigma. Lancet. 2004;363:1147-54.

3. Faculty of Public Health. Hospital mortality rates. 2014.

4. Pitches DW, Mohammed MA, Lilford RJ. What is the empirical evidence that hospitals with higher-risk adjusted mortality rates provide poorer quality care? A systematic review of the literature. BMC Health Serv. Res. 2007;7:91.

5. Kihuba E, Gathara D, Mwinga S, Mulaku M, Kosgei R, Mogoa W, et al. Assessing the ability of health information systems in hospitals to support evidence-informed decisions in Kenya. Glob. Health Action. 2014;7:24859.

6. Bank W. Kenya GDP per capita [Internet]. [cited 2015 Apr 11]. Available from: http://data.worldbank.org/indicator/NY.GDP.PCAP.CD.

7. Kenya National Bureau of Statistics (KNBS). Kenya Demographic Health Survey 2014. 2014

8. Wang H, Liddell C A, Coates MM, Mooney MD, Levitz CE, Schumacher AE, et al. Global, regional, and national levels of neonatal , infant, and under-5 mortality during 1990 - 2013 : a systematic analysis for the Global Burden of Disease Study 2013. Lancet. 2013;1-23.

9. English M, Wamae A, Nyamai R, Bevins B, Irimu G. Implementing locally appropriate guidelines and training to improve care of serious illness in Kenyan hospitals: a story of scaling-up (and down and left and right). Arch. Dis. Child. 2011;96:285-90.

10. Ayieko P, Ntoburi S, Wagai J, Opondo C, Opiyo N, Migiro S, et al. A multifaceted intervention to implement guidelines and improve admission paediatric care in Kenyan district hospitals: a cluster randomised trial. PLoS Med. 2011:8:e1001018.

11. Health M of. Paediatric Abstraction Record (PAR) form [Internet]. [cited 2015 Mar 28]. Available from: http://www.idoc-africa.org/images/ETAT/PAR_basic_ InternshipCentres_\%2025_02_2016-\%20Final.pdf. Data Abstraction Form (Age over 7 days).pdf.

12. Tuti T, Bitok M, Paton C, Makone B, Malla L, Muinga N, Gathara D, English M. Innovating to enhance clinical data management using non-commercial and open source solutions across a multi-center network supporting inpatient pediatric care and research in Kenya. J Am Med Inform Assoc. 2016;23(1):184-192. doi:10.1093/jamia/ocv028.

13. Harris P a, Taylor R, Thielke R, Payne J, Gonzalez N, et al. Research Electronic Data Capture (REDCap) - a metadata driven methodology and workflow process for providing translational research informatict support. J. Biomed. Inform. 2009;42:377-81.

14. World Health Organization; UNICEF. Intergrated Management of Childhood Illnesses [Internet]. WHO. 2014 [cited 2015 Mar 28]. Available from: http:// apps.who.int/iris/bitstream/10665/104772/16/9789241506823_Chartbook_ eng.pdf.

15. Ayieko P, English M. Management of Childhood Pneumonia in Developing Countries. Pediatr Infect Dis J. 2009;26:432-40.

16. Berkley JA, Ross A, Mwangi I, FHA O, Mohammed M, Shebbe M, et al. Prognostic indicators of early and late death in children admitted to district hospital in Kenya: cohort study. BMJ. 2003;326:-361.

17. Conroy AL, Hawkes M, Hayford K, Namasopo S, Opoka RO, John CC, et al. Prospective validation of pediatric disease severity scores to predict mortality in Ugandan children presenting with malaria and non-malaria febrile illness. Crit. Care. 2015;19:1-11.

18. Clifton DC, Ramadhani HO, Msuya L, Njau BN, Kinabo GD, Buchanan AM, Crump JA. Predicting mortality for paediatric inpatients where malaria is uncommon. Arch. Dis. Child. 2012;97:889-94.

19. O'Reilly CE, Jaron P, Ochieng B, Nyaguara A, Tate JE, Parsons MB, et al. Risk factors for death among children less than 5 years old hospitalized with diarrhea in rural Western Kenya, 2005-2007: A cohort study. PLoS Med. 2012; 9:2005-7.

20. $\mathrm{MoH}$. Basic Paediatric Procotols [Internet]. Minist. Heal. 2013 [cited 2015 Mar 28]. Available from: http://www.idoc-africa.org/images/documents/2016/ Basic_Paediatric_Protocol_2016/MAY\%2023rd\%20BPP\%202016\%20SA.pdf.

21. WHO. WHO | Pocket book of hospital care for children: Second edition. WHO Press. World Health Organization; 2013.

22. van Buuren S, Boshuizen HC, Knook DL. Multiple imputation of missing blood pressure covariates in survival analysis. Stat Med. 1999;18:681-94.

23. Raghunathan TE, Lepkowski JM, Van Hoewyk J, Solenberger P. A multivariate technique for multiply imputing missing values using a sequence of regression models. Surv. Methodol. 2001;27:85-95.

24. Rubin Donald. Multiple Imputation for Nonresponse in Surveys. 1987.

25. Multiple imputation FAQ page [Internet]. [cited 2015 Apr 10]. Available from: http://archive.is/4tyn.

26. Jordan J. Louviere, David A. Hensher offre DS. Stated Choice Methods Analysis and Applications. Cambridge University Press; 2000.

27. Gathara D, English $M$, van Hensbroek MB, Todd J, Allen E. Exploring sources of variability in adherence to guidelines across hospitals in low-income settings: a multi-level analysis of a cross-sectional survey of 22 hospitals. Implement. Sci. 2015;10:60

28. Gathara D, Nyamai R, Were F, Mogoa W, Karumbi J, Kihuba E, et al. Moving towards Routine Evaluation of Quality of Inpatient Pediatric Care in Kenya. Choonara I, editor. PLoS One. 2015;10:e0117048.

29. Hospital Standardised Mortality Ratios - Datasets [Internet]. [cited 2015 Apr 14]. Available from: http://data.gov.uk/dataset/hospital_standardised_ mortality_ratios.

30. Vermont Oxford Network - Improving care for infants and their families [Internet]. [cited 2015 Apr 14]. Available from: https://public.vtoxford.org/.

31. Marang-van de Mheen PJ, Shojania KG. Simpson's paradox: how performance measurement can fail even with perfect risk adjustment. BM Qual. Saf. 2014;23:701-5.

32. Kendjo E, Agbenyega T, Bojang K, Newton CRJC, Bouyou-Akotet M, Pedross $F$, et al. Mortality Patterns and Site Heterogeneity of Severe Malaria in African Children. PLoS One. 2013:8

33. A National Pediatric Learning Health System (PEDSnet) | PCORI [Internet]. [cited 2015 Apr 15]. Available from: http://www.pcori.org/research-results/ 2013/national-pediatric-learning-health-system-pedsnet.

34. Sibanda T, Sibanda N. The CUSUM chart method as a tool for continuous monitoring of clinical outcomes using routinely collected data. BMC Med. Res. Methodol. 2007;7:46

35. Steiner SH, Cook RJ, Farewell VT, Treasure T. Monitoring surgical performance using risk-adjusted cumulative sum charts. Biostatistics. 2000;1:441-52.

36. Grunkemeier GL, Wu YX, Furnary AP. Cumulative sum techniques for assessing surgical results THE STATISTICIAN ' S PAGE Cumulative Sum Techniques for Assessing Surgical Results. Ann. Thorac. Surgery. 2003;4975: $663-7$.

37. Cook DA, Coory M, Webster RA. Exponentially weighted moving average charts to compare observed and expected values for monitoring riskadjusted hospital indicators. BMJ Qual. Saf. 2011;20:469-74. 
38. (HISP) HISP. District Health Information System 2 (DHIS2) [Internet]. [cited 2015 Apr 11]. Available from: https://www.dhis2.org/.

39. Schafer JL, Graham JW. Missing data: our view of the state of the art. Psychol. Methods. 2002;7:147-77.

40. Ministry of Health (MoH). Report on the Review of EMR Systems Towards Standardization. 2011.

41. Mamlin BW, Biondich PG. AMPATH Medical Record System (AMRS): collaborating toward an EMR for developing countries. AMIA Annu. Symp. Proc. 2005:490-4.

42. Douglas GP, Gadabu OJ, Joukes S, Mumba S, McKay M V, Ben-Smith A, et al. Using touchscreen electronic medical record systems to support and monitor national scale-up of antiretroviral therapy in Malawi. PLoS Med. 2010;7(8):e1000319. doi:10.1371/journal.pmed.1000319.

Submit your next manuscript to BioMed Central and we will help you at every step:

- We accept pre-submission inquiries

- Our selector tool helps you to find the most relevant journal

- We provide round the clock customer support

- Convenient online submission

- Thorough peer review

- Inclusion in PubMed and all major indexing services

- Maximum visibility for your research

Submit your manuscript at www.biomedcentral.com/submit
Biomed Central 